\title{
Excitotoxicity and Oxidative Stress in Acute Ischemic Stroke
}

\author{
Ramón Rama Bretón ${ }^{1}$ and Julio César García Rodríguez ${ }^{2}$ \\ ${ }^{1}$ Department of Physiology \& Immunology, University of Barcelona \\ ${ }^{2}$ CENPALAB \\ ${ }^{1}$ Spain \\ ${ }^{2} \mathrm{Cuba}$
}

\section{Introduction}

The term "stroke" is applied to a heterogeneous group of diseases caused by decreased perfusion of the brain due to occlusion of the blood vessels supplying the brain or a haemorrhage originating in them. Most strokes $(\sim 85 \%)$ are ischemic; that is, they result from occlusion of a major cerebral artery by a thrombus or embolism. This results in reduced blood flow and a major decrease in the supply of oxygen and nutrients to the affected region. The rest of strokes are haemorrhagic: caused by the rupture of a blood vessel either in the brain or on its surface.

Strokes deprive the brain not only of oxygen but also of glucose and of all other nutrients, as well as disrupting the nutrient/waste exchange process required to support brain metabolism. The result is the development of a hypoxic-ischemic state. Ischemia is defined as a decrease in blood flow to tissues that prevents adequate delivery of oxygen, glucose and others nutrients. Ischemic stroke is the result of total or partial interruption of cerebral arterial blood supply, which leads to oxygen and glucose deprivation of the tissue (ischemia). If cerebral arterial blood flow is not restored within a short period, cerebral ischemia is the usual result, with subsequent neuron death within the perfusion territory of the vessels affected. Ischemic stroke is characterized by a complex sequence of events that evolves over hours or even days [1-3]. Acute ischemic stroke results from acute occlusion of cerebral arteries. Cerebral ischemia occurs when blood flow to the brain decreases to a level where the metabolic needs of the tissue are not met. Cerebral ischemia may be either transient (followed by reperfusion) or essentially permanent. In all cases, a stroke involves dysfunction and death of brain neurons and neurological damage that reflects the location and size of the brain area affected $[1,2]$.

\section{Ischemic core and ischemic penumbra}

Neuropathological analysis after focal brain ischemia reveals two separate areas: the ischemic core, and ischemic penumbra. Once onset of a stroke has occurred, within minutes of focal ischemia occurring, the regions of the brain that suffer the most severe degrees of blood flow reduction experience irreversible damage: these regions are the 
"ischemic core". This area exhibits a very low cerebral blood flow (CBF) and very low metabolic rates of oxygen and glucose [2,3]. Thus, reduced or interrupted CBF has negative effects on brain structure and function. Neurons in the ischemic core of the infarction are killed rapidly by total bioenergetic failure and breakdown of ion homeostasis, lipolysis and proteolysis, as well as cell membrane fragmentation [4]. The result is cell death within minutes [5]. Tissue in the ischemic core is irreversibly injured even if blood flow is re-established.

The necrotic core is surrounded by a region of brain tissue which suffers moderate blood flow reduction, thus becoming functionally impaired but remaining metabolically active; this is known as the "ischemic penumbra" [6]. This metabolically active border region remains electrically silent [7]. From experiments in non-human primates, it has been shown that in this region, the ability of neurons to fire action potentials is lost. However, these neurons maintain enough energy to sustain their resting membrane potentials and when collateral blood flow improves, action potentials are restored. The ischemic penumbra may comprise as much as half the total lesion volume during the initial stages of ischemia, and represents the region in which there is an opportunity to salvage functionality via poststroke therapy $[8,9]$.

Ischemic penumbra refers to the region of brain tissue that is functionally impaired but structurally intact; tissue lying between the lethally damaged core and the normal brain, where blood flow is sufficiently reduced to result in hypoxia that is severe enough to arrest physiological function, but not so complete as to cause irreversible failure of energy metabolism and cellular necrosis [8]. The ischemic penumbra has been documented in laboratory animals as severely hypoperfused, non-functional, but still viable brain tissue surrounding the irreversibly damaged ischemic core [10]. The penumbra can be identified by the biochemical and molecular mechanisms of neuron death [11, 12] and by means of clinical neuroimaging tools $[10,13]$.

Thus, the ischemic penumbra refers to areas of the brain that are damaged during a stroke but not killed. The concept therefore emerges that once onset of a stroke has begun, the necrotic core is surrounded by a zone of less severely reduced blood flow where the neurons have lost functional activity but remain metabolically active. Tissue injury in the ischemic penumbra is the outcome of a complex series of genetic, molecular and biochemical mechanisms, which contribute either to protecting -and then penumbral tissue is repaired and recovers functional activity- or to damaging -and then the penumbral area becomes necrotic -brain cells. Tissue damage and functional impairment after cerebral ischemia result from the interaction between endogenous neuroprotective mechanisms such as anti-excitotoxicity (GABA, adenosine and $\mathrm{K}_{\mathrm{ATP}}$ activation), antiinflammation and anti-apoptosis (IL-10, Epo, Bcl-proteins), and repair and regeneration (c-Src formation, vasculogenesis, neurogenesis, BM-derived cells) on the one hand, with neurotoxic events such as excitotoxicity, inflammation and apoptosis that ultimately lead to cell death, on the other [14]. The penumbra is the battle field where the ischemic cascade with several deleterious mechanisms is triggered, resulting in ongoing cellular injury and infarct progression. Ultimately, the ischemic penumbra is consumed by progressive damage and coalesces with the core, often within hours of the onset of the stroke. However, the penumbra can be rescued by improving the blood flow and/or interfering with the ischemic cascade. At the onset of a stroke, the evolution of the ischemic penumbra is only partially predictable from the clinical, laboratory and imaging methods currently available $[3,10]$. 


\section{Pathophysiological basis of the stroke}

In the last 30 years, experimental and clinical results have led to characterizations of the pathophysiological basis of strokes [1-3]. Cerebral ischemia (ischemic stroke) triggers a complex series of physiological, biochemical, molecular and genetic mechanisms that impair neurologic functions through a breakdown of cellular integrity mediated by ionic imbalance, glutamate-mediated excitotoxicity and also such phenomena as calcium overload, oxidative stress, mitochondrial dysfunction and apoptosis [1-3, 15, 16]. These mediate injury to neurons, glia cells and vascular elements by means of disturbing the function of important cellular organelles such as mitochondria, nuclei, cell membranes, endoplasmic reticula and lysosomes. The result is cell death via mechanisms that promote rupture, lysis, phagocytosis or involution and shrinkage [11, 16]. Knowledge of the molecular mechanisms that underlie neuron death following a stroke is important if we are to devise effective neuroprotective strategies.

We will examine how ischemic injury occurs, which cell death mechanisms are activated, especially excitotoxicity and oxidative stress, and how these can be manipulated to induce neuroprotection. Unfortunately, despite their effectiveness in preclinical studies, a large number of neuroprotectants have failed to produce the desired effects in clinical trials involving stroke sufferers, which suggests that we still lack essential knowledge of the triggers and mediators of ischemic neuron death. We will discuss why, after 30 years or so of intense basic and clinical research, we still find it extremely difficult to translate experimental neuroprotective success in the laboratory to the clinical setting [17-20].

\subsection{Acute ischemic injury in strokes}

Acute ischemic injury is the result of a transient or permanent reduction of CBF in a restricted vascular territory. Normal CBF is between 45 and $60 \mathrm{ml} \mathrm{blood} / 100 \mathrm{~g} / \mathrm{min}$. It is well documented that time-dependent neuronal events are triggered in response to reduced CBF [21, 22]. The brain has critical thresholds for CBF and for oxygen tension. Oxygen supply to the brain below a critical level reduces, and eventually blocks, oxidative phosphorylation, drastically decreases cellular ATP and leads to the collapse of ion gradients. Neuron activity ceases and if oxygen is not re-introduced quickly, cells die [22]. A reduction of cortical blood flow to levels of approximately $20 \mathrm{ml} / 100 \mathrm{~g} / \mathrm{min}$ may be tolerated without functional consequences, but it is associated with the loss of consciousness and ECG alterations. At values of CBF below $18 \mathrm{ml} / 100 \mathrm{~g} / \mathrm{min}$, the tissue infarction is time dependent: $\mathrm{CBF}$ of $5 \mathrm{ml} / 100 \mathrm{~g} / \mathrm{min}$ lasting about 30 minutes cause infarction; CBF of 10 $\mathrm{ml} / 100 \mathrm{~g} / \mathrm{min}$ needs to last for more than 3 hours to cause infarction; permanent CBF below $18 \mathrm{ml} / 100 \mathrm{~g} / \mathrm{min}$ causes irreversible damage [22, 23]. In focal ischemia, complete cessation of blood flow is uncommon because collateral vessels sustain CBF at 5 to $15 \mathrm{ml} / 100$ $\mathrm{g} /$ minute in the ischemic core and at 15 to $25 \mathrm{ml} / 100 \mathrm{~g} /$ minute in the outer areas of the ischemic zone [5, 21, 24]. Global ischemia results from transient CBF below $0.5 \mathrm{ml} / 100$ $\mathrm{g} / \mathrm{min}$ or severe hypoxia to the entire brain. When CBF falls to zero within seconds, loss of consciousness occurs after approximately $10 \mathrm{~s}$, EEG activity ceases after 30-40 s, cellular damage is initiated after a few minutes, and death occurs within $10 \mathrm{~min}$, at least under normothermic conditions [25].

The brain is highly vulnerable to ischemia. In part, the vulnerability of brain tissue to ischemia reflects its high metabolic demands. The brain has a relatively high energy production demand and depends almost exclusively on oxidative phosphorylation for 
energy production. Although the weight of the human brain is only about $2 \%$ of the total bodyweight, it has high metabolic activity and uses $20 \%$ of the oxygen and $25 \%$ of the glucose consumed by the entire body [23]. Proper functioning of brain cells depends on an abundant and continuous supply of oxygen. Even with such high metabolic demands, there is essentially no oxygen storage in cerebral tissue, and only limited reserves of high-energy phosphate compounds and carbohydrate substrates are available. More than $90 \%$ of the oxygen consumed by the brain is used by mitochondria to generate ATP. Energy in the brain is mainly formed when glucose is oxidized to $\mathrm{CO}_{2}$ and water through mitochondrial oxidative phosphorylation. At rest, about $40 \%$ of cerebral energy is used to maintain and restore ionic gradients across cell membrane; even more energy is used during activity [23]. The brain requires large amounts of oxygen to generate sufficient ATP to maintain and restore ionic gradients.

\subsection{Basic mechanisms of ischemic cell death}

After the onset of a stroke, the disruptions to the blood flow in areas affected by vascular occlusion limit the delivery of oxygen and metabolic substrates to neurons causing ATP reduction and energy depletion. The glucose and oxygen deficit that occurs after severe vascular occlusion is the origin of the mechanisms that lead to cell death and consequently to cerebral injury. These mechanisms include: ionic imbalance, the release of excess glutamate in the extracellular space, a dramatic increase in intracellular calcium that in turn activates multiple intracellular death pathways such as mitochondrial dysfunction, and oxidative and nitrosative stress that finally cause neuron death.

After ischemic onset, the primary insult that ischemia causes neurons is a loss of oxygen and glucose substrate energy. While there are potentially large reserves of alternatives substrates to glucose, such as glycogen, lactate and fatty acids, for both glycolysis and respiration, oxygen is irreplaceable in mitochondrial oxidative phosphorylation, the main source of ATP in neurons. Consequently, the lack of oxygen interrupts oxidative phosphorylation by the mitochondria and drastically reduces cellular ATP production, which results in a rapid decline in cellular ATP [26, 27]. Although there are potentially large reserves of substrates such as glycogen, lactate and fatty acids that may be alternatives to glucose, anaerobic metabolism is insufficient to produce sufficient ATP. Reduced ATP stimulates the glycolytic metabolism of residual glucose and glycogen, causing an accumulation of protons and lactate, which leads to rapid intracellular acidification and increases the depletion of ATP [26]. When the lack of oxygen is severe and glucose is diminished, inhibition of oxidative phosphorylation leads to ATP-synthase functioning backwards and consuming ATP, thus contributing to an increase in the loss of ATP [27]. If ATP levels are low, the $\mathrm{Na}^{+} / \mathrm{K}^{+}$-ATPase function fails [27]. After several minutes, inhibition of the $\mathrm{Na}^{+} / \mathrm{K}^{+}$-ATPase function causes a profound loss of ionic gradients and the depolarization of neurons and astrocytes [28]. Membrane depolarization and changes in the concentration gradients of $\mathrm{Na}^{+}$and $\mathrm{K}^{+}$across the plasma membrane result in activation of voltage-gated calcium channels. This leads to excessive release of excitatory amino acids -particularly glutamate- to the extracellular compartment (Fig. 1).

Uncontrolled membrane depolarization by massive changes in the concentration gradients of $\mathrm{Na}^{+}$and $\mathrm{K}^{+}$across the plasma membrane results in a large and sustained release of glutamate and other neurotransmitters to the extracellular compartment [29]. Simultaneously, neurotransmitter re-uptake from the extracellular space is reduced [30, 31]. The rise in the extracellular glutamate concentration initiates a positive feedback loop, with further activation 
of glutamate receptors in neighbouring neurons and as a result, more $\mathrm{Na}^{+}$inflow to neurons via monovalent ion channels that decrease ionic gradients and consume ATP, both of which promote further release of glutamate $[32,33]$. Simultaneously, glutamate transporters in neurons and astrocytes can function backwards, releasing glutamate into the extracellular space $[31,34]$ and contributing to glutamate overload there. A marked and prolonged rise in the extracellular glutamate concentration kills central neurons [2, 11, 32]. Excessive glutamate in the synapses activates the ionotropic glutamate receptors at a pathophysiological level; this type of neuronal insult is called excitotoxicity [29] and is defined as cell death resulting from the toxic actions of excitatory amino acids. Because glutamate is the most important excitatory neurotransmitter in primary perception and constitutes the basis of synaptic transmission in about $10^{14}$ synapses in the human brain, neuronal excitotoxicity usually refers to the injury and death of neurons arising from prolonged intense exposure to glutamate and the associated ionic imbalance in the cell. Excessive activation of glutamate receptors by excitatory amino acids leads to a number of deleterious consequences, including impairment of calcium buffering, generation of free radicals, activation of the mitochondrial permeability transition and secondary excitotoxicity.

Reduction of blood flow

(Ischemic stroke)

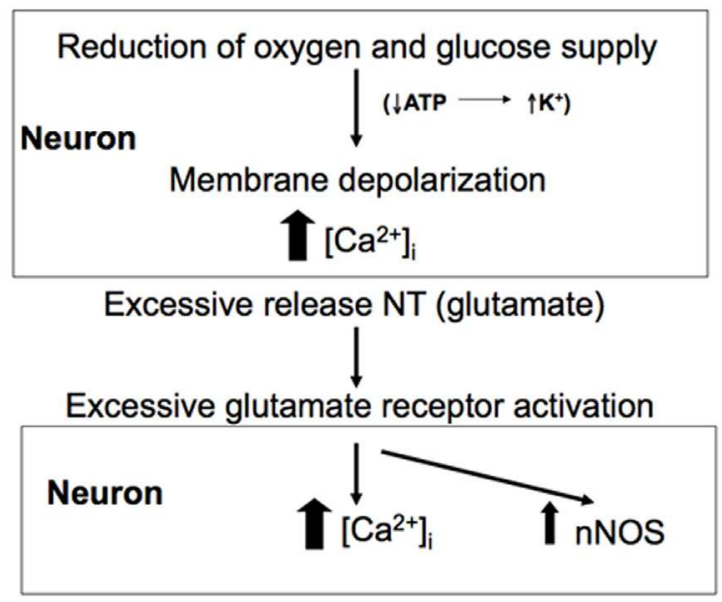

Fig. 1. Excitotoxicity in ischemic stroke. The reduction of blood flow supply to the brain during ischemic stroke results in oxygen and glucose deprivation and thus a reduction in energy available to maintain the ionic gradients. This results in excessive neuronal depolarization and deregulated glutamate release.

\subsection{Excitotoxic mechanisms}

Excitotoxicity is considered to be the central mechanism underlying neuron death in stroke [29, 32-35]. Excitotoxicity is considered to trigger tissue damage in both focal experimental ischemia [34, 36] and clinical ischemia [37]. Glutamate is released at high concentrations in the penumbral cortex [38], particularly if blood flow is reduced for a long period, and the amount of glutamate released correlates with early neurological deterioration in patients 
with acute ischemic stroke [37]. Glutamate concentrations greater than $200 \mathrm{mmol} / \mathrm{l}$ in plasma and greater than $8.2 \mathrm{mmol} / 1$ in CSF are associated with neurological deterioration in the acute phase of cerebral infarction.

The excitotoxic mechanisms which lead to neuron death are complex, but primarily involve the generation of free radicals [35; 39, 40], mitochondrial dysfunction $[41,42]$ and the participation of various transcription factors as activators of gene expression [43,44]. All of these mechanisms acting synergistically can damage cellular proteins [45], lipids [46] and DNA [47, 48], which leads to the deterioration of cellular architecture and signalling, resulting in necrosis, apoptosis or both depending on the severity of the insult and of relative speed of each process [49-51].

\subsection{The role of glutamate receptors in excitotoxicity}

The excitatory effects of glutamate are mediated through two kinds of glutamate receptors ionotropic receptors and metabotropic receptors linked to G-protein [52]- found in the preand post-synaptic neuron membranes of the central nervous system (CNS). Glutamate ionotropic receptors are ligand-gated cation channels permeable to $\mathrm{Ca}^{2+}$. Although virtually all members of the glutamate receptor family are believed to be involved in mediating excitotoxicity [90], $\mathrm{N}$-methyl-d-aspartate (NMDA) glutamate receptors are believed to be the key mediators of death during excitotoxic injury [53].

In recent years, the role of the structure of the NMDA glutamate receptors (NMDARs) in excitotoxicity has caused great therapeutic interest. NMDARs are complex heterotetramer combinations of three major subfamilies of subunits: the ubiquitously expressed NR1 subunit together with one of the four possible NR2 (A-D) subunits and, in some cases, two NR3 (A and B) subunits [54, 55]. Subunit NR1 contains the site where the glutamate is united to the receptor, whereas subunit NR2 contains the site where the glycine is united [56]. The NR3 subunit is present predominantly during brain development [57]. The distinct pharmacological and biophysical properties mediated by NMDARs are largely determined by the type of NR2 subunits incorporated into the heteromeric NR1/NR2 complex [58, 59]. Specific NR2 subtypes appear to play a pivotal role in strokes [60]. In a four-vessel occlusion model of transient global ischemia in rats, the blocking of NMDARs that contained NR2A enhanced neuron death and prevented the induction of ischemic tolerance, whereas inhibiting NMDARs that contained NR2B attenuated ischemic cell death and enhanced preconditioning-induced neuroprotection [61]. It has been suggested that excitotoxicity is triggered by the selective activation of NMDARs containing the NR2B subunit $[61,62]$ and a correlation between NR2B expression, a rise in cytosolic calcium and excitotoxicity was observed in cortical neurons [63]. Because NR2A and NR2B are the predominant NR2 subunits in the adult forebrain, where stroke most frequently occurs, NMDA receptors that contain NR2A and NR2B may play different roles in supporting neuronal survival and mediating neuron death, and hence have opposing impacts on excitotoxic brain damage after acute brain insults such as a stroke or brain trauma [60,61].

NMDARs are found at synaptic or extrasynaptic sites [64, 65]. These different locations on cellular membrane have been considered a determining factor in excitotoxicity after a stroke $[65,66]$. Depending on their location on the cell membrane, activation of NMDARs has dramatically different effects. Evidence suggests that synaptic NMDAR activity is necessary for neuronal survival while the extrasynaptic NMDARs are involved in cell death $[65,66]$. Stimulation of synaptic NMDARs leads to expression of pro-survival proteins, such as BDNF (brain-derived neurotrophic factor) whereas activation of extrasynaptic NMDARs 
leads to expression of pro-apoptotic proteins and suppression of survival pathways [64,65, 67]. However, it has also been postulated that the apparent differences in excitotoxicity mediated by NMDARs could be due to differences in synaptic/extrasynaptic NMDAR molecular composition as opposed to the location of the receptors per se. In adults brain, NMDARs located in synapses predominantly contain the NR2A subtype; while extrasynaptic NMDARs predominantly contain NR2B [67-69]. Although there is little evidence that differences in subunit composition explain the differences between the synaptic and extrasynaptic effects of glutamate, a recent study showed that activation of NMDARs containing NR2B subunits tends to promote neuron death, irrespective of location, whereas activation of NMDARs containing NR2A subunits promotes survival [66]. However, have been shown that NR2A-NMDARs are capable of mediating excitotoxicity [70] and NR2B-NMDARs are capable of mediating both pro-survival and pro-death signalling, depending on the stimulation paradigm [69].

It has further been proposed that lethal Ca2+ signalling by NMDARs is determined by the molecules with which they interact [85]. At the synapse, NMDAR receptors are found localized within electron-dense structures known as the postsynaptic densities (PSDs) where they form large and dynamic multiprotein signalling complexes [71-73]. NMDARs interact with multiple intracellular synaptic and cytoskeletal proteins, mainly through the cytoplasmatic C-termini of the NR1 and NR2 subunits [74, 75]. The PSD is a multiprotein complex that includes a group of proteins called MAGUKs (membrane-associated guanylate kinases) [74-76]. These proteins contain several PDZ (post-synaptic density95/discs large/zonula occludens-1) protein interaction domains through which they are connected to other proteins. PDZ is a common structure domain of 80-90 amino acids found in the signalling proteins. PDZ domains often function as modules in scaffolding proteins that are involved in assembling large protein complexes in the cell [73]. A prominent protein component in the PDZ complex is post-synaptic density-95 (PSD-95) $[74,75]$, which couples NMDARs to intracellular proteins and signalling enzymes. It also functions as a scaffolding and organizer protein of PSD [75, 76]. PSD-95 contains three PDZ domains, of the which the first two (PDZ1 and PDZ2) interact with the C termini of the NMDAR NR2B subunit. The NMDAR is linked to nNOS through the first and second PDZ domains of PSD-95 [76, 77]. Activation of the nNOS by NMDARs leads to the production of excessive levels of nitric oxide (NO) [71]. NO serves as a substrate for the production of highly reactive free radicals such as peroxynitrites, which promote cellular damage and ultimately neuron death [78-80]. Thus, during ischemia, Ca2+ influx through NMDARs promotes cell death more efficiently than through other Ca2+ channels [81], suggesting that proteins responsible for Ca2+-dependent excitotoxicity reside within the NMDAR signalling complex. Disrupting the NMDAR-PSD-95 or nNOS-PSD-95 complexes may reduce the efficiency by which $\mathrm{Ca} 2+$ ions activate excitotoxic signalling through molecules such as nNOS. In cortical neurons, suppression of PSD-95 selectively blocks NO production by NMDARs without affecting NOS expression [71]. In cultured neurons and in experimental animals, through the use of small peptides that disrupted the interaction of NMDARs with PSD-95, neurons were rendered resistant to focal cerebral ischemia [82]. It has been shown that inhibition of the NMDAR/PSD-95 interaction prevents ischemic brain damage, while the physiological function of the NMDAR remains intact [83]. The use of small peptides that bind to the PDZ domains of PSD-95 and block protein-protein interactions protected cultured neurons from excitotoxicity and dramatically reduced cerebral infarction in rats subjected to transient focal cerebral ischemia, and effectively 
improved their neurological function. The treatment was effective when applied either before, or $1 \mathrm{~h}$ after, the onset of excitotoxicity in vitro and cerebral ischemia in vivo [83]. Perturbing NMDAR/PSD-95 interactions with peptides that comprise the nine C-terminal residues of the NR2B subunit reduces the vulnerability of neurons to excitotoxicity and ischemia. Proteomic and biochemical analysis of all the known human PDZs with synaptic signalling proteins that include NR1 or NR2A-NR2D, shows that only neurons lacking PSD-95 or nNOS exhibited reduced excitotoxic vulnerability. Of all the PDZs examined, only PSD-p5 and nNOS participated significantly in excitotoxicity signalling. Thus, despite the ubiquity of proteins that contain the PDZ domain, the importance of the role of PSD-95 and nNOS over and above that of any other PDZ proteins in mediating NMDAR-dependent excitotoxicity was recently demonstrated [70]. Deletion of the PSD-95 dissociates NMDAR activity from NO production and suppresses excitotoxicity [84].

It remains an open question whether the death of neurons is mediated by different types of NMDAR subunits $[66,68]$ or only by distinct locations of the receptors $[64,65]$. It is possible that $\mathrm{Ca}^{2+}$ toxicity is linked to the route of $\mathrm{Ca}^{2+}$ entry and the different second messenger pathways activated by $\mathrm{Ca}^{2+}$ entry [85].

Perhaps consideration of the NMDARs as the route to excitotoxicity is over-simplistic, since others mechanisms may be involved [86]. AMPA receptors are not normally calcium permeable due to their GluR2 subunit, nevertheless, after ischemia this subunit is reduced and the permeability of these receptors by calcium increases 18 -fold, allowing AMPARs to contribute to increased intracellular calcium [87]. As just mentioned, injury during stroke may result from $\mathrm{Ca}^{2+}$-overload due to overstimulation of AMPA receptors together with indirect $\mathrm{Ca}^{2+}$ entry through gated voltage-channels, $\mathrm{Ca}^{2+}$-permeable acid-sensing ion channels [88], activation of metabotropic glutamate receptors via the release of $\mathrm{Ca}^{2+}$ from endoplasmic reticulum and via a cleavage of $\mathrm{Na}^{+} / \mathrm{Ca}^{2+}$ exchangers [89]. Consequently, it seems that in relation to the mechanisms that mediate cell death in stroke, the more important factor is the amount of cytosol $\mathrm{Ca}^{2+}$ free to accumulate and not the route of entry.

\section{5 $\mathrm{Ca}^{2+}$ cytoplasmic overload, mitochondria dysfunction and oxidative stress}

After a stroke, as a consequence of excessive extracellular glutamates, NMDARs are excessively activated resulting in increased $\mathrm{Ca}^{2+}$ influx $[35,81,84]$. Calcium plays a critical role in the excitotoxic cascade, because either removing $\mathrm{Ca}^{2+}$ from extracellular medium [90] or preventing $\mathrm{Ca}^{2+}$ from entering mitochondria by uncouplers [91] protects neurons against excitotoxic injury. There is strong evidence that perturbed cellular $\mathrm{Ca}^{2+}$ homeostasis is pivotal in the death of neurons following a stroke [35, 81, 84, 92]. It is now well established that a strong relationship exists between excessive $\mathrm{Ca}^{2+}$ influx and glutamate-triggered neuronal injury during stroke [2, 43, 93]. The earliest studies of the mechanisms resulting in neuron death as a consequence of glutamate excitotoxicity established the essential role of calcium in neuron cell death resulting from excessive NMDAR activation [93-95]. Sustained overstimulation of NMDARs leads to $\mathrm{Ca}^{2+}$ and $\mathrm{Na}^{+}$ overload in postsynaptic neurons $[92,94,95]$. After ischemia, cytoplasmic $\mathrm{Ca}^{2+}$ levels rise to $50-100 \mu \mathrm{M}$. Such excessive $\mathrm{Ca}^{2+}$ levels can trigger many downstream neurotoxic cascades $[35,92,94,95]$, including the activation and overstimulation of proteases, lipases, phosphatases and endonucleases (Fig. 2). The results include the activation of several signalling pathways, mainly causing an overproduction of free radicals, dysfunction of mitochondria, cell membrane disruption, and DNA fragmentation, which acting synergistically cause neuron death [1, 2, 11, 84, 96]. 


\section{Ischemia}
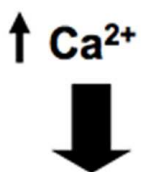

Calpains, phospholipase $A_{2}$, protein kinases, endonucleases, NOS, mitochondrial dysfunction
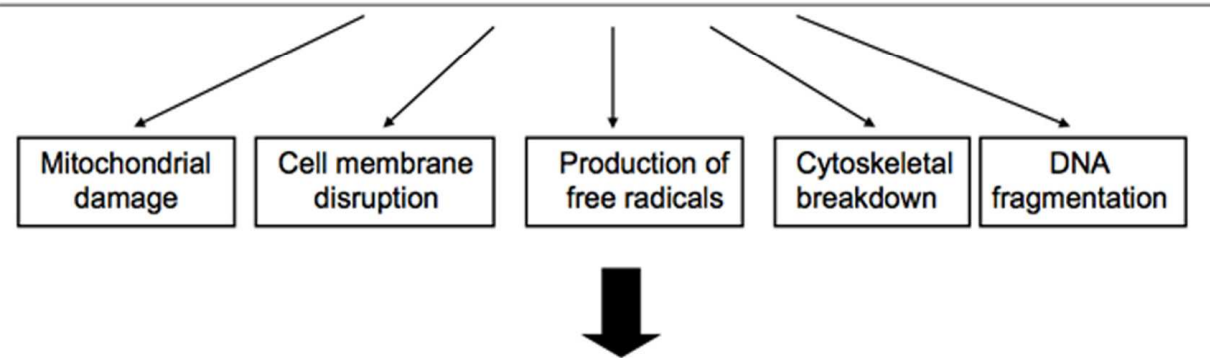

APOPTOTIC OR NECROTIC NEURON DEATH

Fig. 2. Effects of very high $\mathrm{Ca}^{2+}$ accumulation in neurons after ischemia. Excitotoxicity causes a sudden increase in cytoplasmic $\mathrm{Ca}^{2+}$ concentrations in neurons after ischemia, which induces activation of several signaling pathways, leading to apoptototic or necrotic neuronal death. Activation of calpains, caspases, other proteases, kinases and endonucleases, cause mitochondrial disturbance, overproduction of free radicals and DNA fragmentation, that synergistically lead to neuronal death.

Major excitotoxic events promoted by cytoplasmic $\mathrm{Ca}^{2+}$ overload due to massively activated glutamate receptors include mitochondrial dysfunction, oxidative/nitrosative stress and calpain activation (Fig. 3).

The excitotoxicity can contribute to neuron death by altering the functions of mitochondria. Mitochondrial disturbance is the result of both oxidative-nitrosative stress and a direct effect of excessive $\mathrm{Ca}^{2+}$ intracellular levels. Mitochondrial dysfunction is caused by free radicals and the mitochondrial disturbance, in turn, increases the production of free radicals. Mitochondria play an important role in calcium homeostasis $[97,98]$. Under conditions of cytoplasmic excess of $\mathrm{Ca}^{2+}$, mitochondria are very important for cell survival, as they have the ability to sequester large amounts of $\mathrm{Ca}^{2+}$. From in vitro studies [98] it can be inferred that mitochondria within intact neurons will act as temporary reversible stores of $\mathrm{Ca}^{2+}$, accumulating the cation when cytoplasmic $\mathrm{Ca}^{2+}$ is above a set point, and releasing the cation back to the cytoplasm when the plasma membrane $\mathrm{Ca}^{2+}$-ATPase succeeds in pumping down cytoplasmic $\mathrm{Ca}^{2+}$ to below the set point $[96,99]$. For this cytoplasmic buffering to occur with no deleterious effects for the mitochondria and hence the cell, the time during which cytoplasmic $\mathrm{Ca}^{2+}$ is above the set point must be brief, thus avoiding mitochondrial $\mathrm{Ca}^{2+}$ overload [96]. During stroke, electron microscope analyses show that $\mathrm{Ca}^{2+}$ accumulates in mitochondria very soon after global ischemia and this state persists for several hours [100]. Excessive and prolonged uptake of $\mathrm{Ca}^{2+}$ in mitochondria causes mitochondrial dysfunction [41, 96, 101], which is considered the primary event in neuron death due to excitotoxicity [41]. 


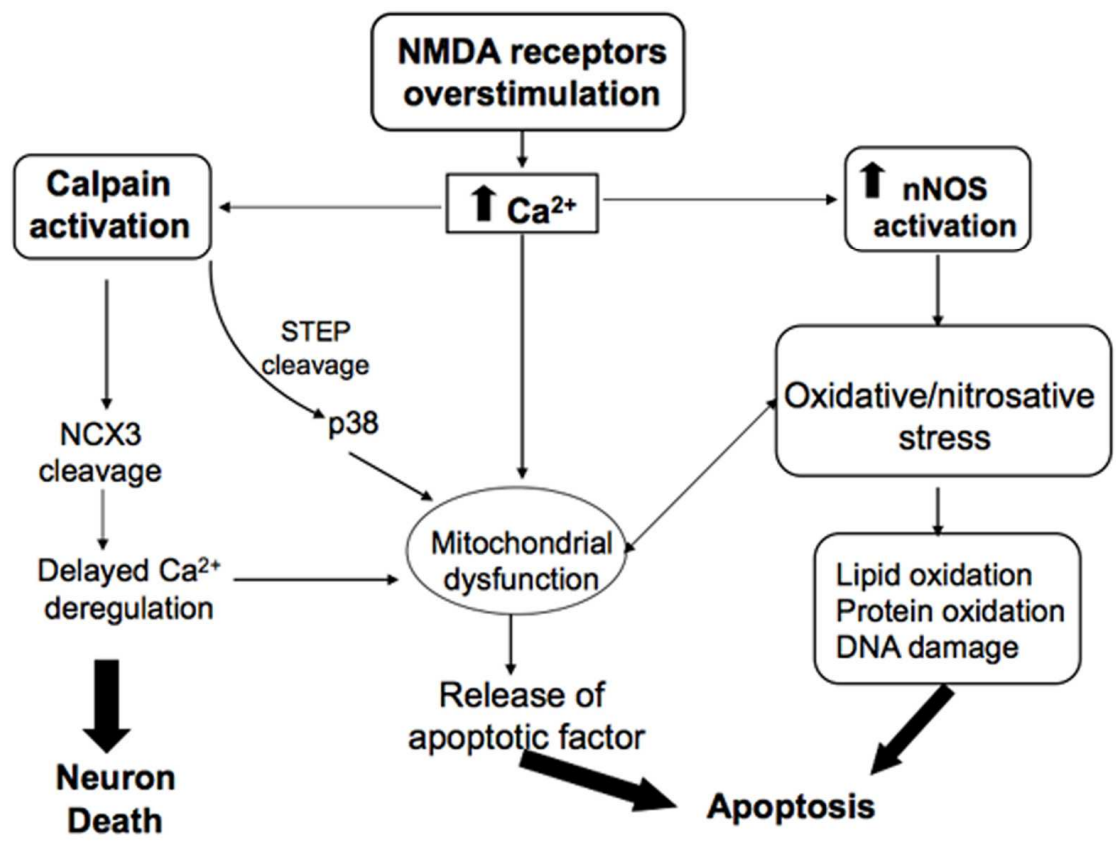

Fig. 3. Excitotoxic signaling by overstimulation of the NMDA receptors. Major excitotoxic events promoted by extrasynaptic NMDAR activation. Cerebral ischemia elevates cytosolic $\mathrm{Ca}^{2+}$ levels through the stimulation of NMDARs. The calcium overload: a) activates calpains that inactivate of the $\mathrm{Na}^{+} / \mathrm{Ca}^{2+}$ exchanger (NCX3), b) induces mitochondrial disturbance that activate intrinsic apoptotic pathway and c) activates NOS that increases the NO production. Higher concentrations of nitric oxide can produce irreversible modifications of proteins, lipids and impairment of mitochondrial respiration. All of these processes trigger pathological mechanisms leading to neuronal death.

Mitochondrial dysfunction as a consequence of prolonged accumulation of $\mathrm{Ca}^{2+}$ is considered a major source of free radicals that are generated after ischemia-reperfusion [102, 103]. As a result of the mitochondrial dysfunction induced by the free $\mathrm{Ca}^{2+}$ cytosol accumulation, two events seem to play an important role in the death of neurons: the increase in the production of free radicals associated with a diminution of the antioxidant defences [102, 103], and the induction of the apoptotic cascade (Fig. 4) [104, 105].

Under physiological conditions, free radicals are generated at low levels and play important roles in signalling and metabolic pathways (106-108]. However, free radicals avidly interact with a large number of molecules including other small inorganic molecules as well as proteins, lipids, carbohydrates, and nucleic acids. Through such interactions, free radicals may irreversibly destroy or alter the function of the target molecule. Consequently, free radicals have been increasingly identified as major contributors to damage in biological organisms. The significance of free radicals as aggravating or primary factors in numerous pathologies is firmly established [109, 110]. 
Importantly, free radicals are produced continually during normal oxidative metabolism, but there are counteracted by a sophisticated system of enzymes and non-enzymatic antioxidants which maintains physiological homeostasis [111](Fig. 5). Enzymatic components mainly comprise superoxide dismutases (SOD) [112], catalases [111], glutathione [113] glutathione reductase/glutathione peroxidases (GR/GPX) [114], and peroxiredoxins [115]. Also, small molecular non-enzymatic antioxidants are important in scavenging free radicals. These include ascorbic acid, pyruvate, $\alpha$-tocopherol and glutathione, which are also involved in the detoxification of free radicals, provision of antioxidant defence and prevention of tissue damage [111].

\section{Excessive glutamate receptor activation}

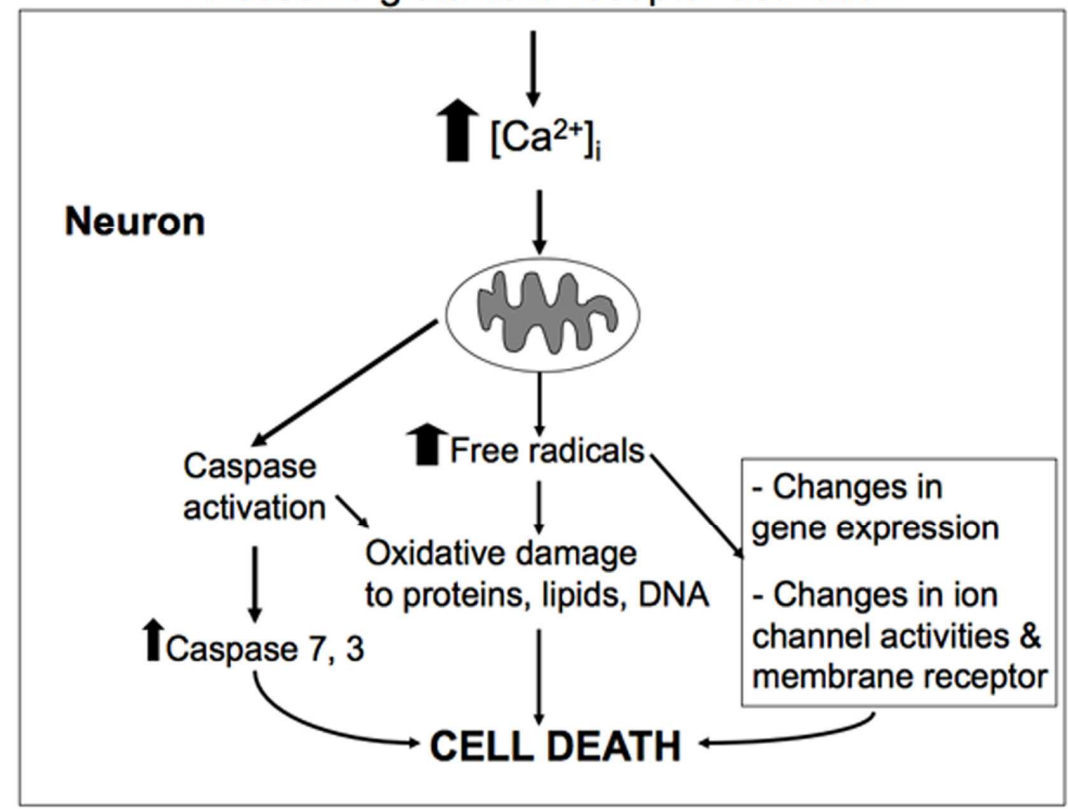

Fig. 4. Mitochondrial dysfuntion by disruption of calcium homeostasis leads to oxidative stress and apoptosis. Mitochondria are involved in both, the necrosis and the apoptotic pathways, which depend on the severity of the insult or nature of the signaling pathways. When cytosolic $\mathrm{Ca}^{2+}$ reaches non-physiological levels, the mitochondrial membrane may become more permeable, which causes release of cytochrome $\mathrm{c}$ and activation of the apoptotic pathway. $\mathrm{Ca}^{2+}$-induced mitochondria disturbance involves dysfunction of ETC, increased ROS and oxidative stress.

When an imbalance occurs, either by increasing free radical formation or decreased antioxidant defences, and the formation of free radicals exceeds the protective capacity of antioxidant systems, the accumulation of free radicals is known as a state of "oxidative stress" [116]. Oxidative stress is generally defined as an imbalance that favours the production of free radicals over their inactivation by antioxidant defence systems [117]. 


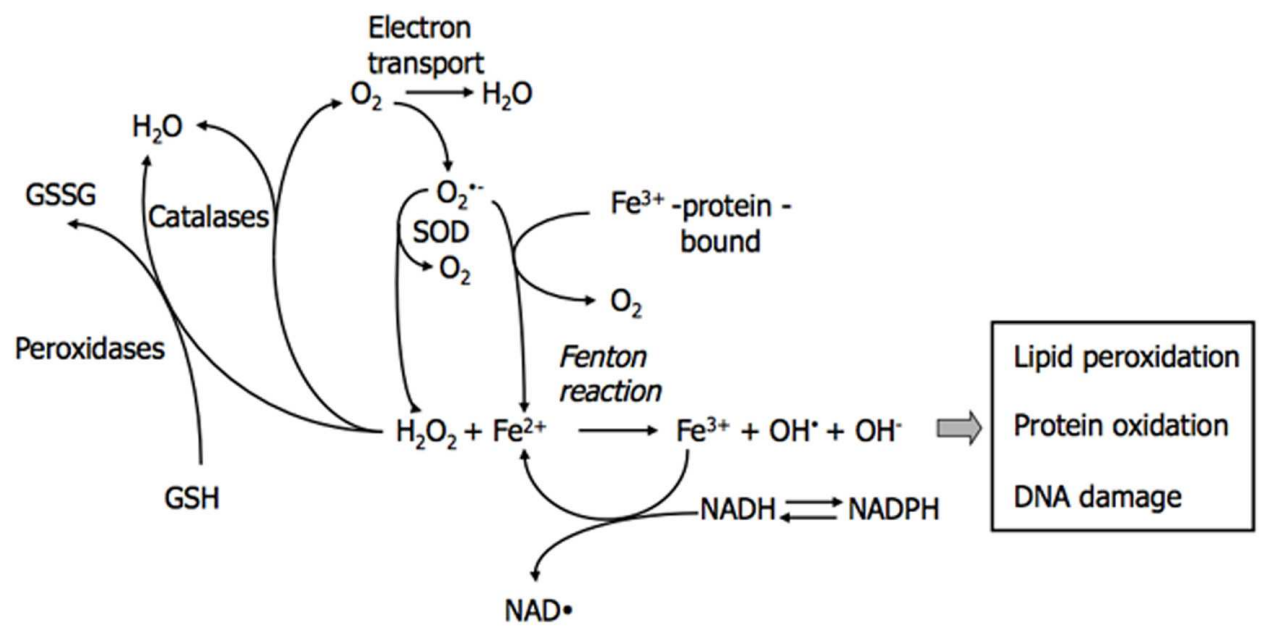

Fig. 5. Cellular reactions lead to oxidative damage of lipids, proteins and DNA via the Fenton reaction and their protection by main endogenous antioxidant enzymes (SOD, catalases and proxidaxes). The deleterious effects of ROS and RNS are controlled by antioxidant defences. Neurons are particularly vulnerable to oxidative stress owing to their high metabolic activity and oxygen consumption, which leads to high levels of ROS production, together with relatively low levels of endogenous antioxidant enzymes, particularly catalase. Moreover, the high lipid content of the brain can react with ROS to generate peroxyl radicals, leading to lipid oxidation of the neuronal membrane. The combination of these factors makes the CNS particularly vulnerable to oxidative damage.

Oxidative stress induced by excitotoxicity is considered the main event leading to brain damage after cerebral ischemia [35, 103, 109]. The most important free radicals induced by excitotoxicity are molecular derivates of oxygen and oxide nitric. Owing to their high oxidizing power, the intermediate reduction states of oxygen are called reactive oxygen species (ROS) and nitrogen-containing oxidants are called reactive nitrogen species (RNS). ROS are small oxygen-derived molecules, including the superoxide anion radical $\left(\mathrm{O}_{2}{ }^{\bullet-}\right)$, hydroxyl radical $(\mathrm{OH})$, and certain non-radicals that are either oxidizing agents or easily converted into radicals, such as hydrogen peroxide $\left(\mathrm{H}_{2} \mathrm{O}_{2}\right)$ and the oxygen singlet $\left({ }^{1} \mathrm{O}_{2}\right)$. RNS are nitrogen-derived molecules, such as nitric oxide $(\mathrm{NO} \cdot)$, which has a relatively long half-life (approx. $1 \mathrm{~s}$ ) and whose reactions with biological molecules are slow due to its very rapid diffusion into the blood and consequent inactivation by haemoglobin. $\mathrm{NO}^{\bullet}$ is an important free radical because it combines with $\mathrm{H}_{2} \mathrm{O}_{2}$ and $\mathrm{O}_{2}{ }^{-}$to form $\mathrm{OH}^{\bullet}$ and peroxynitrite $\left(\mathrm{ONOO}^{-}\right)$, which is stable at an alkaline $\mathrm{pH}$ and fairly non-reactive, but it is readily protonated at cellular $\mathrm{pH}$ to peroxynitrous acid $(\mathrm{ONOOH})$, which is very cytotoxic.

Following early suggestions [118], free radicals and other small reactive molecules have emerged as important players in the cell mechanisms involved in the pathophysiology of strokes [35, 119-121]. Several lines of research indicate that oxidative stress is a primary mediator of neurologic injury following cerebral ischemia [103, 120,121]. After cerebral ischemia and particularly reperfusion, robust oxidants are generated including superoxide and hydroxyl radicals, which overwhelm endogenous scavenging mechanisms [122, 123] 
and are directly involved in the damage to cellular macromolecules, such as lipids, proteins, and nucleic acids, eventually leading to cell death [1,2] (Fig. 6). Re-oxygenation during reperfusion provides oxygen to sustain neuronal viability and also provides oxygen as a substrate for numerous enzymatic oxidation reactions that produce reactive oxidants. In addition, reflow after occlusion often causes an increase in oxygen to levels that cannot be utilized by mitochondria under normal physiological flow conditions. During reperfusion, perturbation of the antioxidative defence mechanisms is a result of the overproduction of oxygen radicals, inactivation of detoxification systems, consumption of antioxidants, and failure to adequately replenish antioxidants in the ischemic brain tissue [122-123].

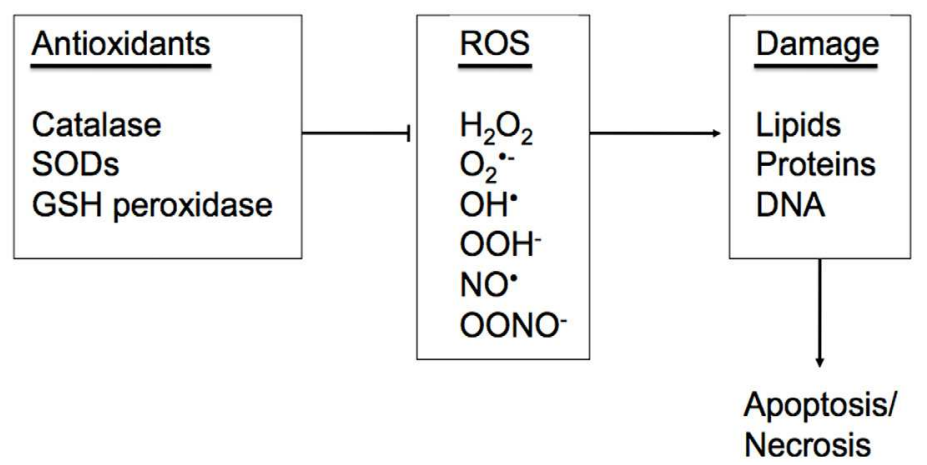

Fig. 6. ROS-mediated damage of cellular macromolecules may lead to neuron death. Excessive release of glutamate can trigger ROS increase. Antioxidant defences include several enzymes. In the healthy subjects, there is a balance between the production of antioxidants defences and of reactive species. When an imbalance occurs, either by increasing free radical formation and/or decreased anti-oxidant defences, and the formation of free radicals exceeds the protective capacity of antioxidant systems, the accumulation of free radicals leads to oxidative stress.

The important role of free radicals in cell damage during stroke is emphasized by the fact that even delayed treatment with the use of antioxidants and inhibitors of free radical producing enzymes can be effective in experimental focal cerebral ischemia [124, 125]. In addition, the overproduction of radical-scavenging enzymes protects against stroke [126] and animals that are deficient in radical-scavenging enzymes are more susceptible to cerebral ischemic damage [127]. In addition, neuroprotection is evident in animal models where genes coding for enzymes that promote oxidative stress are knocked down or out, and where genes coding for antioxidant enzymes, e.g., superoxide dismutase (SOD) are over-expressed [44, 126].

Increased levels of ROS and RNS generated extra- and intra-cellularly can, by various processes, initiate and promote neuron death during ischemic stroke. ROS and RNS can directly oxidize and damage macromolecules such as DNA, proteins, and lipids, culminating in neuron death[1, 2, 45-47]. ROS and RNS can also indirectly contribute to tissue damage by activating a number of cellular pathways resulting in the expression of stress-sensitive genes and proteins that cause oxidative injury [43].

Intracellular sources of ROS include the mitochondrial electron transport chain (ETC), xanthine oxidase, arachidonic acid, and NADPH oxidases. It is generally thought that 
mitochondria are the primary source of ROS involved in oxidative stress induced after cerebral ischemia. Free radicals are produced in the mitochondria as by-products of respiratory chain reactions. While passing through the mitochondrial ETC, some electrons escape from the mitochondrial ETC, especially from complexes I and III, and react with $\mathrm{O}_{2}$ to form superoxide anion radicals $\left(\mathrm{O}_{2}{ }^{-}\right)$(Figure 7), which rapidly dismutate to $\mathrm{H}_{2} \mathrm{O}_{2}$ either spontaneously, particularly at low $\mathrm{pH}$, or catalyzed by superoxide dismutase [128, 129]. Approximately $1 \%-2 \%$ of the molecular oxygen consumed during normal physiological respiration is converted into superoxide radicals [130].

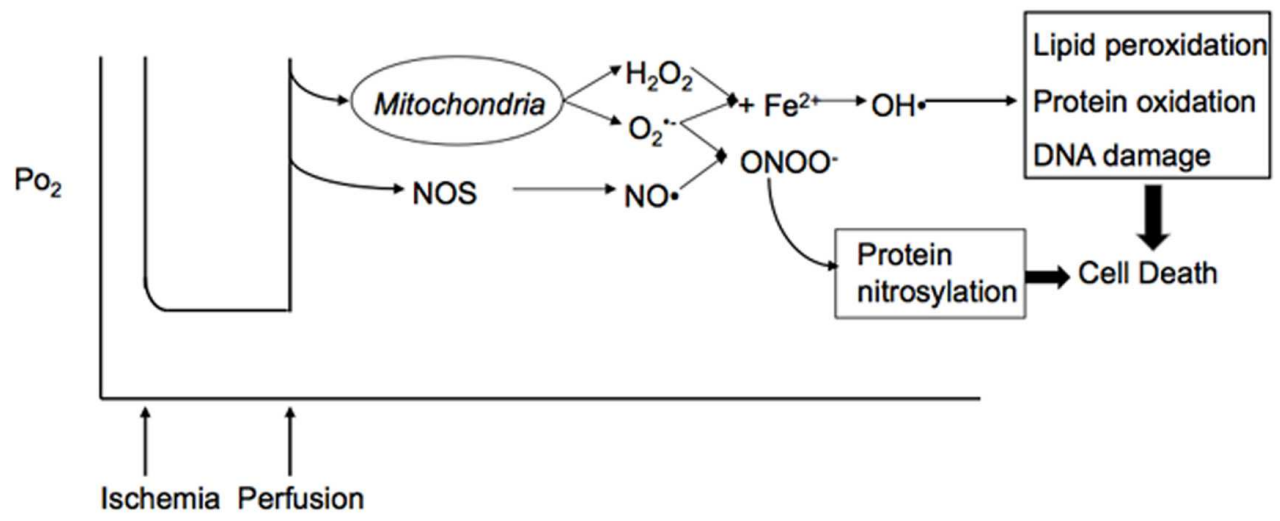

Fig. 7. Cerebral ischemia and reperfusion generated reactive oxygen species by mitochondria and reactive nitrogen species by nitric oxide synthase. The generation of peroxynitrite (ONOO-), formed by the reaction of nitric oxide with superoxide anion, and subsequent hydroxil radical $\left(\mathrm{OH}^{\circ}\right)$ production can directly damage lipids, proteins, and DNA and lead to neuron death.

\section{Oxidative stress in acute ischemic stroke}

Neurons are particularly vulnerable to oxidative stress owing to their high metabolic activity and oxygen consumption which lead to high levels of ROS production, together with relatively low levels of endogenous antioxidant enzymes, particularly catalase [131]. Moreover, the high lipid content of the brain can react with ROS to generate peroxyl radicals that lead to neuron membrane lipid oxidation [132]. The combination of these factors makes the CNS particularly vulnerable to oxidative damage [113].

The primary source of free radical generation in cells during cerebral ischemia has been reported to be due to a decrease in mitochondria redox potential causing ROS production from the ETC, mainly at the level of cytochrome III [102, 103, 118, 130]. After ischemia, an excess of cytosolic free $\mathrm{Ca}^{2+}$ due to excitotoxicity may overload the mitochondrial proton circuit, which leads to failure in oxidation together with increased ROS production [102, 109]. Overproduction of ROS by mitochondria causes the impairment of the ETC, which in turn, leads to decreased ATP production, increased formation of free radicals, altered calcium homeostasis and mitochondrial dysfunction [130]. In the rat, transient middle cerebral artery occlusion (MCAO) induces ROS production and mitochondrial dysfunction, including the inactivity of ETC enzymes. The mitochondrial dysfunction is attenuated by treatment with an 
antioxidant [133] or by the over-expression of mitochondrial Hsp70/Hsp75 [134], both of which decrease the ROS concentration.

Although mitochondrial dysfunction has been considered as a major source of ROS, other excitotoxic pathways may also be important in inducing oxidative stress. Recently, it has been suggested that NADPH oxidase is the primary source of superoxide production following neuronal NMDAR activation [135]. All NADPH oxidase (NOX) family members are transmembrane proteins that transport electrons across biological membranes. In general, the electron acceptor is oxygen and the product of the electron transfer reaction is $\mathrm{O}_{2}{ }^{-}$. The biological function of NOX enzymes is therefore the generation of ROS. NADPH oxidase was originally described in neutrophils, but has subsequently been identified in many other cell types including neurons [136]. While NMDAR activation induces $\mathrm{O}_{2}{ }^{-}$ production by NADPH oxidase, a near-complete absence of $\mathrm{O}_{2}{ }^{\cdot-}$ production was observed in neurons lacking functional NADPH oxidase and in neurons in which NADPH oxidase function had been inhibited. Markedly reduced NMDA neurotoxicity was also observed under these conditions [137].

During the ischemic phase, some $\mathrm{Ca}^{2+}$-dependent enzymes, such as phospholipase $\mathrm{A}_{2}\left(\mathrm{PLA}_{2}\right)$ and cyclooxygenase (COX), produce oxygen free radicals. It has been shown that PLA $\mathrm{A}_{2}$ levels increase in the brain within 2-30 min of ischemia [138]. The activation of $\mathrm{PLA}_{2}$ by $\mathrm{Ca}^{2+}$ results in the release of arachidonic acid from the phospholipids, which is further metabolized by cyclooxygenase to eicosanoids along with the production of free radicals [139]. Cyclooxygenase catalyzes the addition of two $\mathrm{O}_{2}$ molecules to arachidonic acid to produce the prostaglandina $\mathrm{PGG}_{2}$, which in turn is rapidly peroxidized to $\mathrm{PGH}_{2}$ with a simultaneous release of $\mathrm{O}_{2}{ }^{--}[11,140]$. In addition, PLA 2 activation generates lysophosphatides that alter membrane structures. Activation of $\mathrm{PLA}_{2}$ and cyclooxygenase generates free-radical species that overwhelm endogenous scavenging mechanisms, producing lipid peroxidation and membrane damage $[2,140]$.

During stroke, a high influx of $\mathrm{Ca}^{2+}$ through NMDA receptors may lead to the activation of nNOS and increase the production of NO [71, 77]. As described above, in neurons, $\mathrm{NO}^{-}$is produced by neuronal NO synthase (nNOS), an enzyme tethered to the NMDA receptor complex by the postsynaptic density protein-95 (PSD95) [71]. During stroke NO production in the brain increases dramatically due to the activation of the neuronal and inducible isoforms of nitric oxide synthases [79]. The $\mathrm{NO} \cdot$ combines with $\mathrm{H}_{2} \mathrm{O}_{2}$ and $\mathrm{O}_{2}{ }^{\bullet}-$ to form $\mathrm{OH} \cdot$ and peroxynitrite $\left(\mathrm{ONOO}^{-}\right)$[141]. which is generated at high levels and strongly contributes to ischemic brain damage [79]. After ischemia an important target of $\mathrm{NO}$-induced $\mathrm{ONOO}^{-}$is mitochondria causing mitochondrial dysfunction and the consequent increased generation of oxygen free radicals leading to prompt dysfunction of cellular membranes causing necrosis. The ROS generated from the ETC can readily react with NO to form the highly reactive peroxynitrite, which can damage lipids, proteins and DNA [45-47, 79]. Mitochondrial $\mathrm{Ca}^{2+}$ overload, concomitant generation of free radicals, and depression of cell energy metabolism are thought to play important roles in the pathogenesis of ischemic brain damage $[35,36,84,101]$. There is increasing evidence that NO is involved in the mechanisms of cerebral ischemia [78, 80]. After MCAO, the NO concentration in the ischemic area increases to micromolar levels. The surge in NO concentration can be inhibited by glutamate receptor antagonists, which show that increased production of NO is initiated by glutamate $[78,80]$. In a clinical study in patients with acute ischemic stroke, increased NO metabolite in CSF was associated with greater brain injury and early neurological deterioration [142]. 
The $\mathrm{H}_{2} \mathrm{O}_{2}$ formed from $\mathrm{O}_{2}{ }^{\cdot-}$ has two possible fates: (i) conversion to hydroxyl radical $\left(\mathrm{OH}^{\bullet}\right)$, the most reactive free radical produced in biological systems, by means of the Haber-Weiss reaction $\left(\mathrm{H}_{2} \mathrm{O}_{2}+\mathrm{O}_{2}{ }^{--} \rightarrow \mathrm{O}_{2}+\mathrm{OH}^{\bullet}+\mathrm{OH}^{-}\right)$[143] which is favoured by iron ions in Fenton reaction $\left(\mathrm{Fe}^{2+}+\mathrm{H}_{2} \mathrm{O}_{2} \rightarrow \mathrm{Fe}^{3+}+\mathrm{OH}^{\bullet}+\mathrm{OH}^{-}\right)$[144] or (ii) conversion to water by oxidation of the small tripeptide glutathione (GSH) via a reaction catalyzed by the enzyme glutathione peroxidase (GPX) $\left(\mathrm{H}_{2} \mathrm{O}_{2}+2 \mathrm{GSH} \rightarrow \mathrm{GSSG}+2 \mathrm{H}_{2} \mathrm{O}\right)$ or mutated to water and oxygen $\left(\mathrm{H}_{2} \mathrm{O}_{2} \rightarrow\right.$ $\mathrm{H}_{2} \mathrm{O}+1 / 2 \mathrm{O}_{2}$ ) by the catalase enzyme [106]. Reduction of the oxidized glutathione (GSSG) in a reaction catalyzed by glutathione reductase creates more GSH, which then converts more $\mathrm{H}_{2} \mathrm{O}_{2}$ to $\mathrm{H}_{2} \mathrm{O}$ (Fig. 8). About $1 \%$ of the mitochondrial ROS escape elimination by antioxidant defence mechanisms. The major contribution of mitochondria to cytosolic ROS comes from $\mathrm{H}_{2} \mathrm{O}_{2}$ escaping the GPX degradation in the matrix and by residual $\mathrm{O}_{2}{ }^{-{ }^{-}}$, which can enter the cytosol via the porin (VDAC). The greatest oxidative cellular damage produced by superoxide, however, is derived from its participation in peroxinitrite $\left(\mathrm{ONOO}^{-}\right)$formation $\left(\mathrm{O}_{2}{ }^{\cdot-}+\mathrm{NO}^{\bullet} \rightarrow \mathrm{ONOO}^{-}\right)[141]$

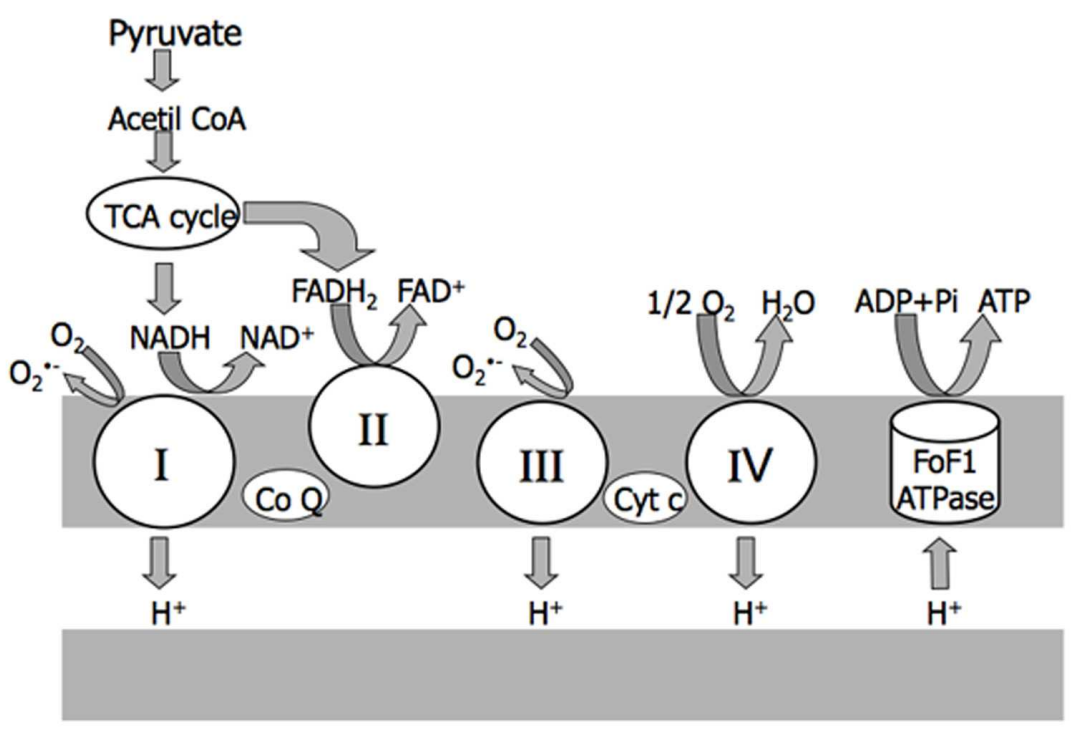

IMM

OMM

\section{Cytosol}

Fig. 8. The neurons, under physiological conditions, generate ATP mainly by mitochondrial phosphorylation via the electron transport chain (ETC). In this process, mainly complexes I and III carry out electrons to molecular oxygen, serving as the primary source of superoxide production. IMM: Inner mitochondrial membrane, OMM: Outer mitochondrial membrane.

Oxidative/nitrosative stress may damage different cellular components, including oxidation of membrane lipids [132], essential cell proteins [145] and DNA [48] as well as initiating cascade reactions, which lead to mitochondrial dysfunction [109] caspase activation [146] and the activation of signal transduction pathways [14], which finally lead to neuron death. On the basis of experimental models, there is ample evidence for enhanced free radical production in the brain after stroke [1-3, 35, 120, 121]. 


\section{Apoptotic mechanisms after cerebral ischemia}

After ischemia, excitotoxicity can lead to apoptotic or necrotic cell death [65-68]. The route involved depends on the time elapsed, the intensity of the stimulus and the degree to which energy production is maintained. While necrosis occurs mainly in the earliest moments after the onset of ischemia in the core [2,49-51], programmed cell death begins hours later and lasts for several days [104]. This delayed cell death occurs mainly in the penumbra and is thus temporally and spatially different from the rapid necrotic neuron death in the core.

There are two general pathways for activation of apoptosis: the extrinsic and intrinsic pathways. Studies of tissue from patients and of animal models have shown that mitochondria-mediated apoptosis is the mode by which many neurons die after an acute stroke [105]. Oxidative stress and cytotoxic accumulation of intracellular $\mathrm{Ca}^{2+}$ initiate a series of cytoplasmic and cellular events, including the triggering of the intrinsic apoptotic pathway (Figure 9) [2, 105]. Increased ROS/RNS and intracellular free $\mathrm{Ca}^{2+}$ levels mediate induction/activation of pro-apoptotic proteins such as prostate apoptosis response $4(\operatorname{Pr} 4)$, pro-apoptotic Bcl-2 members (Bax, Bad and others) and p53 [147], leading to changes in the mitochondrial membrane permeability (MMP) [148]. Proteins in the anti-apoptotic Bcl-2 family as well as anti-apoptotic kinase Akt and ERK protect the mitochondrial integrity by inhibiting pro-apoptotic Bcl-2 family members. Following cerebral ischemia, several proapoptotic members of the Bcl-2 family (tBid, Dp-5, Bim, Bax, Bak, and BAD) may antagonize the anti-apoptotic Bcl-2 family proteins to induce mitochondrial damage. Once the balance is shifted towards apoptosis, the mitochondria release apoptotic proteins such as cyt-c and AIF [104]. Alterations in expression of members of the Bcl-2 protein family, including increased expression of Bax and Bad, and reduced expression of Bcl-2 and Bcl-w, are found in the ischemic core and in the penumbra of the infarct [14]. A rapid translocation of cytosolic Bax to the mitochondria has been observed after cerebral ischemia [149]. After the opening of the mitochondrial pores, pro-apoptotic proteins are released into the cytosol; these include cytochrome $c$ (cyt $c$ ) and Smac/DIABLO [149]. The release of cyt $c$ and other pro-apoptotic proteins can trigger caspase activation and apoptosis. Once released into the cytosol from the mitochondrial intermembrane space, cyt $c$ binds with apoptotic proteinactivating factor-1 (Apaf-1) and procaspase-9 to form an "apoptosome", which actives caspase- 9 and subsequently caspase-3. Activated caspase- 3 dismantles a wide range of homeostatic, reparative and cytoskeletal proteins including nDNA repair enzymes, such as poly (ADP-ribose) polymerase (PARP), and activates caspase-activated DNase (CAD) [149] which cleaves nuclear DNA and leads to DNA damage and neuron cell death. Apoptotically damaged mitochondria also release other factors, such as AIF and EndoG, to facilitate DNA fragmentation and Smac/DIABLO to facilitate caspase activation [149]. There is a large body of evidence suggesting that cerebral ischemia can cause activation of caspases, certain types of protease that can cleave a larger number of cellular substrates [14, 105, 146]. Up regulation and activation of caspase- 3 have been found to precede neuron death in focal and global cerebral ischemia [104].

Experiments involving manipulation of the molecular systems linked to the pathogenesis of apoptosis suggest that apoptosis is involved in neuron death following focal ischemic insults. Over-expression of human BCL-2 [150] reduces infarction in rodent brains subjected to focal ischemic insults. In addition, p53 knock-out transgenic mice also exhibit reduced brain vulnerability to focal ischemic insults. Interestingly, a greater protective effect was seen in heterozygous animals than in animals that were homozygous for the p53 null gene, which is consistent with some beneficial actions of p53 and some gene dose effect [151]. 


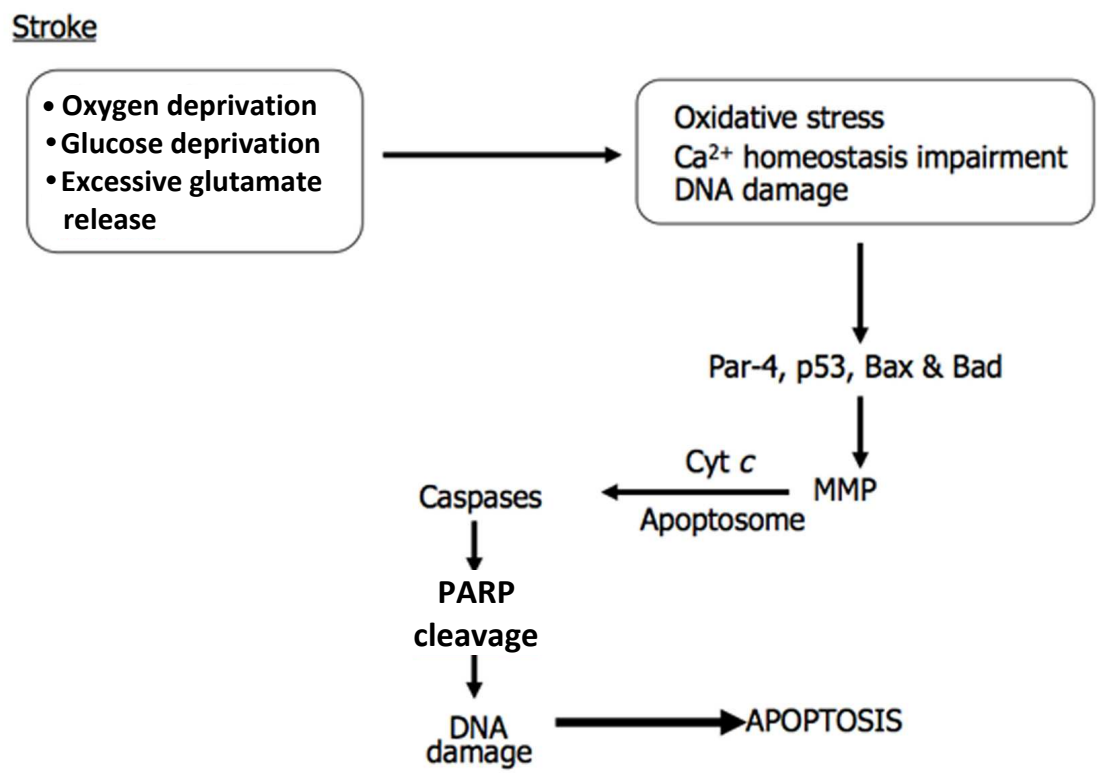

Fig. 9. The intrinsic apoptosis pathway in neurons is initiated by moderate overactivation of glutamate receptors, oxidative stress and DNA damage. The apoptotic trigger often activate transcriptions factor such as p53 that induce the expression of the pro-apoptotic Bcl-2 family members bax and bad which increased permeability of the outer mitochondrial membrane and the subsequent release of cytochrome $\mathrm{c}$ to the cytosol. In the cytosol, cytochrome $\mathrm{c}$ binds to the apoptosome which then activitates the caspase cascade that, in turn, cleaves numerous protein substrates leading to the neuronal death.

\section{The role of calpains in strokes}

One of the key events induced after ischemia by $\mathrm{Ca}^{2+}$ overload is a massive activation (either directly or indirectly) of calpains, important contributors to excitotoxic cell death [152]. The calpain family consists of about 15 members of cellular cysteine proteases that are activated by calcium in the cytosol [153]. Calpains can modulate a variety of physiological processes [153]. Regulated activation of calpains in the CNS may be critical to synaptic function and memory formation. All calpains can act in two modes: under physiological conditions they undergo controlled activation (involving only a few molecules of calpain) whereas during sustained calcium overload under pathological conditions they undergo hyperactivation (involving all the available calpain molecules) [152].

Although neurons behave very differently in acute and chronic cerebral ischemia, there is a pervasive view that $\mathrm{Ca}^{2+}$-dependent calpain protease inhibitors are protective to varying degrees in animal models of stroke [154,155]. Ample evidence documents the activation of calpains in brain ischemia and excitotoxic neuronal degeneration [152, 156]. Two mechanisms have recently been suggested which involve calpains as mediators of neuron death in strokes. In a rat model of focal ischemia, $\mathrm{Ca}^{2+}$-overload activated calpain cleavage of $\mathrm{Na}^{+} / \mathrm{Ca}^{2+}$ exchangers (NCX) thus precluding the possibility of restoring NCX [157], which are among the most potent regulators of $\mathrm{Ca}^{2+}$ concentrations in neuronal cells, and are a 
contribute to $\mathrm{Ca}^{2+}$ cytosol accumulation during ischemia [87, 89]. Cleavage of NCX leads to an irreversible increase in the intracellular $\mathrm{Ca}^{2+}$ concentration. The inhibition of calpain prevents cleavage of NCX and prevents the secondary $\mathrm{Ca}^{2+}$ overload linked to neuronal demise [89]. So, calpain activation by excessive cytoplasmic $\mathrm{Ca}^{2+}$ can contribute to the mediation of cleavage of NCX and increase cytoplasmic calcium deregulation [157].

\section{Anti-excitotoxic mechanisms and their potential as therapeutic targets}

In the treatment of acute cerebral ischemia, two primary therapeutic strategies are applied: (1) limitation of cerebral ischemia by early reperfusion after cerebral ischemia (the vascular approach), and (2) interference with the patho-biochemical cascade leading to ischemic damage (the neuroprotective approach) [158]

\subsection{The vascular approach}

After many years without any therapeutic treatment for strokes, and since seminal studies $[6,7]$ showed the existence of an ischemic penumbra where neurons maintain membrane potential for several hours or more after the onset of a stroke, recanalization therapies that aim to recover the flow of blood in the ischemic penumbra have been developed.

The results of the intravenous application the tissue plasminogen activator (tPA) to reopen occluded blood vessels [159] led the US Food and Drug Administration to approve the use of tPA for treatment of acute ischemic stroke in 1996. The early recovery of blood flow in the cerebral ischemic region is the principal factor that prevents neuronal injury. Early recanalization with thrombolytic therapy clearly improves patient outcome after an acute stroke [159]. The use of tPA therapy when administered intravenously within the first $3 \mathrm{~h}$, significantly improves patient outcome by approximately $30 \%$. In addition, tPA is the only drug licensed and available for treatment of ischemic stroke that can lead to a recanalization of occluded vessels and to an improvement in clinical outcome. However, less than $5 \%$ of potentially eligible patient are currently being treated with tPA therapy in the USA or in Europe [160] and the use of tPA therapy remains limited. The reasons for this situation are complex, but in clinical practice the main obstacle is the narrow therapeutic time window, currently limited to $3 \mathrm{~h}$, together with insufficient public knowledge of the stroke warning signs, the small number of centres able to administer thrombolysis on a 24-h basis and also some physicians' excessive fear of haemorrhagic complications [161]. The use of tPA is associated with an increased risk of intracerebral haemorrhage (ICH) and mortality [162] and it requires sophisticated pre-treatment imaging [163].

\subsection{The neuroprotective approach}

The second major therapeutic approach, neuroprotection, aims: to rescue ischemic tissue and improve functional outcome by intervention on the ischemic cascade; and to reduce the intrinsic vulnerability of brain tissue to ischemia. Cellular neuroprotective approaches have focused mainly on blocking excitotoxicity, that is, neuron death triggered by the excitatory transmitter glutamate, and mediated by cytotoxic levels of calcium influx. Many experimental trials have demonstrated that many agents are effective in infarction volume reduction in animal models of stroke but have not been successfully translated to humans [164]. Neuroprotective strategies have failed to show clinical benefit despite promising laboratory results. Unfortunately, to date, none of tested neuroprotective agents has been shown to improve outcomes in phase III clinical trials [165]. All attempts to find effective neuroprotective 
drugs for the treatment of strokes have failed to demonstrate unequivocal efficacy in clinical trials [166]. Because the brain is a complex organ that is capable of many intricate functions, it has proved difficult to develop drugs for the treatment of neurodegenerative disorders that do not interfere with the normal functioning of the nervous system.

Preclinical research require rigorous attention to a variety of variables that may influence the outcome. The widely touted STAIR criteria represent constructive guidelines for preclinical testing [167] but, as experience has shown, have not increased the translational success. The failure to translate these strategies from the laboratory to clinical trials is a disappointment and many agents have been brought to clinical trial despite only modest or inconsistent preclinical evidence of neuroprotective efficacy.

These recurrent clinical failures might be due to heterogeneous populations of stroke patients, drug-associated toxicity at the doses required for efficacy. They may also be due to low dose administration, irregular study design and inadequate statistical evaluation, the limited time window required for initiating treatment, or the lack of adequate CNS penetration across the blood-brain barrier (BBB) [165]. The future of neuroprotection is seen to lie in concentrating on the subgroup of patients with an existing penumbra, the combination of neuroprotection and thrombolysis and in prophylactic neuroprotection. Current therapeutic targets have focused on the preservation of the ischemic penumbra in the hope of improving clinical outcomes. Neuroprotective strategies may aid in prolonging time windows, thereby potentially increasing the number of patients who could benefit from reperfusion treatments. Reperfusion therapies are rapidly evolving and have been shown to improve clinical outcomes. There has been significant progress with successful reperfusion treatments associated with improved clinical outcomes. The use of neuroprotective agents to prolong time windows prior to reperfusion or to prevent reperfusion injury may present future therapeutic targets for the treatment of ischemic stroke.

In recent years, over a thousand experimental and over four hundred clinical studies have been published. A close survey of the most extensively evaluated neuroprotection agents and their classes as well as the results of the clinical trials, have been published [164, 165, 168]. The outcome at the clinical trial phase of some compounds for the treatment of acute ischemic stroke, are shown (Table 1) [18].

These considerations have led to the possibility of a future multidrug therapeutic approach that will probably have to include peptide growth factors for early induction of survival of signal transduction and recovery of translational competence, inhibition of calpain, inhibition of radical damage, and caspase inhibition. Rigorous studies to establish such an approach will require the evaluation of neurologic and histopathologic outcomes as well as of the molecular endpoints associated with each component to establish the role of each drug. Such a multi-factorial therapeutic approach to molecular injury mechanisms now appears essential for the development of substantially improved reperfusion.

A new neuroprotective therapy opens interesting and hopeful perspectives. It is becoming increasingly clear that erythropoietin (Epo) is potentially neuroprotective in different models of brain injury [169-171]. Epo exerts its effects through the activation of the neuronal erythropoietin receptor (EpoR), part of the cytokine-receptor type I superfamily, where it acts as an anti-apoptotic, antioxidant, anti-inflammatory and neurothropic factor. Numerous preclinical findings and some clinical pilot studies [170-172] suggest that recombinant human Epo (rHuEpo) provides neuroprotection that may be beneficial in the treatment of patients suffering from ischemic stroke. Epo theoretically represents an ideal compound for neuroprotection, not only against strokes, but also against other brain disease. (See the chapter devoted to this issue in this book). 


\begin{tabular}{|c|c|c|c|c|}
\hline Compound & Mechanism of action & \begin{tabular}{|l|} 
Inclusion \\
period (h)
\end{tabular} & Outcome (Phase) & Reason $^{b}$ \\
\hline Selfotel & NMDA receptor antagonist & 6 & Negative (III) & Adverse events \\
\hline Aptiganel & NMDA receptor antagonist & 6 & Negative (III) & Lack of efficacy \\
\hline Gavestinel & $\begin{array}{l}\text { NMDA glycine-site } \\
\text { antagonist }\end{array}$ & 6 & Negative (III) & Lack of efficacy \\
\hline Eliprodil & $\begin{array}{c}\text { NMDA, polyamine site } \\
\text { blocker }\end{array}$ & 6 & Negative (II) & Adverse events \\
\hline $\begin{array}{l}\text { Magnesium } \\
\text { sulphate }\end{array}$ & NMDA, channel blocker & 12 & Negative (III) & Lack of efficacy \\
\hline Cervene & $\begin{array}{c}\text { Kappa opioid receptor } \\
\text { antagonist }\end{array}$ & 6 & Negative (III) & Lack of efficacy \\
\hline Lubeluzole & $\begin{array}{c}\text { NOS inhibitor and } \mathrm{Na}+ \\
\text { channel blocker }\end{array}$ & 8 & Negative (III) & Lack of efficacy \\
\hline Fosphenytoin & Sodium channel blocker & 6 & Negative (III) & Lack of efficacy \\
\hline BMS-204352 & K+-channel blocker & 6 & Negative (III) & Lack of efficacy \\
\hline \multirow[t]{2}{*}{$\begin{array}{c}\text { Calcium } \\
\text { antagonists }\end{array}$} & $\mathrm{Ca} 2+$ channel antagonists & $6-24$ & Negative & \\
\hline & & & (Meta-analysis) & Lack of efficacy \\
\hline \multirow[t]{2}{*}{ Enlimomab } & Anti-ICAM antibody & 6 & Negative (III) & Lack of efficacy \\
\hline & & & & and adverse events \\
\hline Citicoline & Cell membrane stabilizer & 24 & Negative (III) & Lack of efficacy \\
\hline Clomethiazole & GABAA receptor mimetic & 12 & Negative (III) & Lack of efficacy \\
\hline Tirilazad & Lipid peroxidation inhibitor & $4-24$ & Negative (III) 6 trials & Lack of efficacy \\
\hline Ebselen & Lipid peroxidation inhibitor & $12-48$ & Negative (II) & Lack of efficacy \\
\hline Repinotan & 5-HT1A receptor antagonist & 6 & Negative (IIb) & Lack of efficacy \\
\hline \multirow[t]{2}{*}{ ONO-2506 } & Astrocyte modulating factor & 6 & Negative (II) & Lack of efficacy in \\
\hline & & & & futility analysis \\
\hline Trafermin & Basic fibroblast growth factor & 6 & Negative (II/III) & Lack of efficacy \\
\hline \multirow[t]{2}{*}{ UK-279,276 } & Neutrophil inhibitory factor & 6 & Negative (II) & Lack of efficacy in \\
\hline & & & & Futility analysis \\
\hline
\end{tabular}

a Abbreviations: BMS-204352, [35]-[+]-[5-chloro-2-methexyphenyl]-1,3-dihydro-3-fluoro-6-

[trifluoromethyl]-2H-indol-2-one; ICAM, intercellular adhesion molecule; NMDA, N-methyl-

Daspartate;

NOS, nitric oxide synthase.

${ }^{\mathrm{b}}$ Lack of efficacy means that efficacy was not demonstrated.

From Green A \& Shuaib A. Drug Discovery Today 11(15/16) 681-694 (2006).

Table 1. Some compounds that have failed in clinical evaluation for the treatment of acute ischaemic stroke ${ }^{a}$

\section{Conclusions}

After the onset of a stroke, the disruptions to the blood flow in areas affected by vascular occlusion limit the delivery of oxygen and metabolic substrates to neurons causing ATP reduction and energy depletion. The glucose and oxygen deficit that occurs after severe vascular occlusion is the origin of the mechanisms that lead to cell death and consequently to cerebral injury. These mechanisms include: ionic imbalance, the release of excess glutamate in the extracellular space, a dramatic increase in intracellular calcium that in turn activates multiple intracellular death pathways such as mitochondrial dysfunction, and oxidative and nitrosative stress that finally cause neuron death. 
During more than two decades, many neuroprotect drugs have emerged as potent inhibitors with different targets of the ischemic cascade in acute stroke. However, until now none of them succeeded in clinical trials. Despite the potential of Epo in animal models that enhanced resistance of the neurons to glutamate toxicity and other positive effects in different targets of ischemic cascade, Epo or its no erythropoietic variants as Neuro-EPO may be overcome by alternative non-traumatic administration methods, such as intranasal delivery.

Many questions remain unanswered yet concerning this new molecule of Epo, which will try to be answered in the next chapter as we always learn from past mistakes in developing new drugs to stroke. A more biological basis is necessary in preclinical experimental research. This is the prerequisite to design an adequate molecule and administration delivery system. Finally, we want to give the reader a novel vision of how to face the acute treatment of the stroke with the application of Neuro-EPO via nasal. This will be the fundamental objective of the following chapter, in explaining the quick clinic application of this new molecule by nasal delivery for acute stroke therapy.

\section{References}

[1] Lo EH, Dalkara T, Moskovitz MA. Mechanisms, challenges and opportunities in stroke. Nat Rev Neurosci 4: 399-415 (2003).

[2] Dirnagl U, Iadecola C, Moskovitz MA. Pathobiology of ischemic stroke: an integrated view. Trends Neurosci 22: 391-397 (1999).

[3] Moustafa RR, Baron J-C. Pathophysiology of ischaemic stroke: insights from imaging, and implications for therapy and drug discovery. Br J Pharmacol 153: S44-S54 (2008).

[4] Martin RL, Lloyd HG, Cowan AI. The early events of oxygen and glucose deprivation: setting the scene for neuronal death? Trends Neurosci 17: 251-257 (1994).

[5] Hossmann KA. Viability thresholds and the penumbra of focal ischemia. Ann Neurol 36: 557-565 (1994).

[6] Astrup J, Symon L, Branston NM, Lassen NA. Cortical evoked potential and extracellular $\mathrm{K}^{+}$and $\mathrm{H}^{+}$at critical levels of brain ischemia. Stroke 8: 51-57 (1977).

[7] Astrup J, Siesjo BK, Symon L. Thresholds in cerebral ischemia -the ischemic penumbra. Stroke 12: 723-725 (1981).

[8] Ginsberg MD. Adventures in the pathophysiology of brain ischemia: penumbra, gene expression, neuroprotection: the 2002 Thomas Willis lecture. Stroke 34: 214-223 (2003).

[9] Markus R, Reutens DC, Kazui S, Read S, Wright P, Pearce DC, Tochon-Danguy HJ, Sachinidis JI, Donnan GA. Hypoxic tissue in ischaemic stroke: persistence and clinical consequences of spontaneous survival. Brain 127:1427-1436 (2004).

[10] Baron JC. Mapping the ischaemic penumbra with PET: implications for acute stroke treatment. Cerebrovasc Dis 9:193-201 (1999).

[11] Lipton P. Ischemic cell death in brain neurons. Physiol Rev 79: 1431-1568 (1999).

[12] Mehta SL, Manhas N, Raghubir R. Molecular targets in cerebral ischemia for developing novel therapeutics. Brain Res Rev 54: 34-66 (2007).

[13] Heiss WD. Ischemic penumbra: evidence from functional imaging in man. J Cereb Blood Flow Metab 20:1011-1032 (2000). 
[14] Ferrer I, Planas AM. Signaling of cell death and cell survival following focal cerebral ischemia: Life and death struggle in the penumbra. J Neuropathol Exper Neurol 62: 329-339 (2003).

[15] Mergenthaler P, Dirnagl U, Meisel A. Pathophysiology of the stroke: lessons from animal models. Metab Brain Dis 19: 151-167 (2004).

[16] Hossmann KA. Pathophysiology and therapy of experimental stroke. Cell Mol Neurobiol 26:1057-1083 (2006).

[17] Cheng YD, Al-Khoury L, Zivin JA. Neuroprotection for ischemic stroke: two decades of success and failure. NeuroRx 1:36-45 (2004)

[18] Green RA, Shuaib A. Therapeutic strategies for the treatment of stroke. Drug Des Today 11:681-693 (2006).

[19] Zhang ZG, Chopp M. Neurorestorative therapies for stroke: underlying mechanisms and translation to the clinic. Lancet Neurol 8: 491-500 (2009).

[20] Zaleska MM, Mercado MLT, Chavez J, Feuerstein GZ, Pangalos MN, Wood A. The development of stroke therapeutics: Promising mechanisms and translational challenges. Neuropharmacol 56: 329-341 (2010).

[21] Heiss WD. Flow threshold of functional and morphological damage of brain tissue. Stroke 14: 329-331 (1983).

[22] Erecinska M, Silver IA. Tissue oxygen tension and brain sensitivity to hypoxia. Resp Physiology 128: 263-276 (2001).

[23] Zauner A, Daugherty WP, Bullock MR, Warner DS. Brain oxygenation and energy metabolism. Neurosurgery 51: 289-301 (2002).

[24] Obrenovitch TP. The ischaemic penumbra: twenty years on. Cerebrovasc Brain Metab Rev 7: 297-323 (1995).

[25] Kulik T, Kusano Y, Aronhime S, Sandler AL, Winn HR. Regulation of cerebral vasculature in normal and ischemic brain. Neuropharmacology 55: 281-288 (2008).

[26] Martin RL, Lloyd HG, Cowan AI. The early events of oxygen and glucose deprivation: setting the scene for neuronal death? Trends Neurosci 17: 251-257 (1994).

[27] Katsura K, Kristian T, Siesjo BK. Energy metabolism, ion homeostasis, and cell damage in the brain. Biochem Soc Trans 22: 991-996 (1994).

[28] Hansen AT, Nedergaard M. Brain ion homeostasis in cerebral ischemia. Neurochem Pathol 9: 195-209 (1988).

[29] Rothman SM, Olney JW. Glutamate and the pathophysiology of hypoxic-ischemic brain damage. Ann Neurol 19: 105-111 (1986).

[30] Camacho A, Massieu L. Role of glutamate transporters in the clearance and release of glutamate during ischemia and its relation to neuronal death. Arch Med Res 37: 1118 (2006).

[31] Rossi DJ, Oshima T, Attwell D. Glutamate release in severe brain ischaemia is mainly by reversed uptake. Nature 403: 316-321 (2000).

[32] Choi DW, Rothman SM. The role glutamate neurotoxicity in hypoxic-ischemic neuronal death. Ann Rev Neuron 13: 171-178 (1990).

[33] Hossmann KA. Glutamate-mediate injury in focal cerebral ischemia: the excitotoxin hypothesis revised. Brain Pathol 4: 23-36 (1994).

[34] Choi DW. Excitotoxic cell death. J Neurobiol 23: 1261-1276 (1992).

[35] Siesjo BK, Zhao Q, Pahlmark K, Siesjo P, Katsura K, Folbergrova J. Glutamate, calcium and free radicals as mediators of ischemic brain damage. Ann Thorac Surg 59: 13161320 (1995). 
[36] Arundine M, Tymiansky M. Molecular mechanisms of glutamate-dependent neurodegeneration in ischemia and traumatic brain injury. Cell Mol Life Sci 61: 657668 (2004).

[37] Castillo J, Dávalos A, Noya M. Progression of ischaemic stroke and excitotoxic aminoacids. Lancet 349: 79-83 (1997).

[38] Takagi K, Ginsberg MD, Globus MY, Dietrich WD, Martínez E, Kraydieh S, Busto R. Changes in amino acid neurotransmitters and cerebral blood flow in the ischemic penumbral region following middle cerebral artery occlusion in the rat: Correlation with histopathology. J Cereb Blood Flow Metab 13: 575-585 (1993).

[39] Pelligrini-Giampietro DE, ChericiG, Alesiani M, Carla V, Moroni F. Excitatory amino acid release and free radical formation may cooperate in the genesis of ischemiainduced neuronal damage. J Neurosci 10: 1035-1041 (1990).

[40] Oh SM, Betz L. Interaction between free radicals and excitatory amino acids in the formation of ischemic brain edema in rats. Stroke 22: 915-921 (1991).

[41] Shinder AF, Olson EC, Spitzer NC, Montal M. Mitochondrial dysfunction is a primary event in glutamate neurotoxicity. J Neurosci 16: 6125-6133 (1996).

[42] Nicholls DG, Budd SL. Mitochondria and neuronal glutamate excitotoxicity. Biochim Biophys Acta 1366: 97-112 (1998).

[43] Akins PT, Liu PK, Hsu CY. Immediate early gene expression in response to cerebral ischemia. Stroke 27: 1682-1687 (1996).

[44] Clemens JA. Cerebral ischemia: gene activation, neuronal injury, and the protective role of antioxidants. Free Radic Biol Med 28: 1526-1531 (2000).

[45] Berlett BS, Stadtman ER. Protein oxidation in aging, disease, and oxidative stress. J Biol Chem 272: 20313-20316 (1997).

[46] Sakamoto A, Ohnishi ST, Ohnishi T, Ogawa R. Relationship between free radical production and lipid peroxidation during ischemia-reperfusion injury in the rat brain. Brain Res 554: 186-192 (1991).

[47] Hayashi T, Sakurai M, Itoyama Y, Abe K. Oxidative damage and breakage of DNA in the rat brain after transient MCA occlusion. Brain Res 832: 159-163 (1999).

[48] Cui J, Holmes EH, Greene TG, Liu PK. Oxidative DNA damage precedes DNA fragmentation after experimental stroke in rat brain. FASEB J 14: $955-967$ (2000).

[49] Bonfoco E, Krainc D, Ankarcrona M, Nicotera P, Lipton SA. Apoptosis and necrosis: two distinct events induced, respectively, by mild and intense insults with $\mathrm{N}$ methyl-D-aspartate or nitric oxide/superoxide in cortical cell cultures. Proc Natl Acad Sci U S A 92:7162-7166 (1995).

[50] Nicotera P, Leist M, Manzo L. Neuronal cell dath: a demise with different shapes. Trends Pharmacol Sci 20: 46-51 (1999).

[51] Ünal-Çevik I, Kilinç M, Can A, Gürsoy-Ózdemir, Dalkara T. Apoptotic and necrotic death mechanisms are concomitantly activated in the same cell after cerebral ischemia. Stroke 35: 2189-2194 (2004).

[52] Nakanishi S. Molecular diversity of glutamate receptors and implications of brain functions. Science 258: 597-603 (1992).

[53] Waxman EA, Lynch DR. N-methyl-D-aspartic receptor subtypes: multiple role in excitoxicity and neurological disease. Neuroscientist 11: 37-49 (2005).

[54] Madden DR.: The structure and function of glutamate receptor ion channels. Nat Rev Neurosci 3: 91-101 (2002).

[55] Paoletti P, Neyton J. NMDA receptor subunits: function and pharmacology. Curr Opin Pharmacol 7: 39-47 (2007). 
[56] Clements JD, Westbrook GL. Activation kinetics reveals the number of glutamate and glycine binding sites on the $N$-methyl-D-aspartic receptor. Neuron 7: 605-613 (1991).

[57] Wong H-K, Liu X-B, Matos MF, Chan SF, Pérez-Otaño I, Boysen M, Cui J, Nakanishi N, Trimmer JS, Jones EG, Lipton SA, Sucher NJ. Temporal and regional expresión of NMDA receptor subunit NR3A in the mammalian brain. J Comp Neurol 450: 303317 (2002).

[58] Lynch DR., Guttmann RP. NMDA receptor pharmacology perspectives from molecular biology. Curr Drug Targets 2: 215-231 (2001).

[59] Furukawa, H., Singh, S. K., Mancusso, R. \& Gouaux, E. Subunit arrangement and function in NMDA receptors. Nature 438: 185-192 (2005).

[60] Liu Y, Wong TP, Aarts M, Rooyakkers M, Liu L, Lai TW, Wu DC, Lu J, Tymianski M, Craig AM, Wang YT. NMDA receptor subunits have differential roles in mediating excitotoxic neuronal death both in vitro and in vivo. J Neurosci 27: 2846-2857 (2007).

[61] Chen M, Lu TJ, Chen XJ, Zhou Y, Chen Q, Feng XY, Xu L, Duan WH, Xiong ZQ. Differential roles of NMDA receptor subtypes in ischemic neuronal cell death and ischemic tolerance. Stroke 39: 3042-3048 (2008).

[62] Zhou M, Baudry M. Developmental changes in NMDA neurotoxicity reflect developmental changes in subunit composition of NMDA receptors. J Neurosci 26: 2956-2963 (2006).

[63] Cheng C, Fass DM, Reynolds IJ. Emergence of excitotoxicity in cultured forebrain neurons coincides with larger glutamate-stimulated $\left[\mathrm{Ca}^{2+}\right] i$ increases and NMDA receptor mRNA levels. Brain Res 849: 97-108 (1999).

[64] Hardinghan GE, Fu-kunaga Y, Bading H. Extrasynaptic NMDARs oppose synaptic NMDARs by triggering CREB shut-off and cell death pathways. Nat Neurosci 5 : 405-414 (2002).

[65] Sattler R, Xiong Z, Lu WY, MacDonald JF, Tymianski M. Distinct roles of synaptic and extrasynaptic NMDA receptors in excitotoxicity. J Neurosci 20: 22-23 (2000).

[66] Liu Y, Wong TP, Aarts M, Rooyakkers M, Liu L, Lai TW, Wu DC, Lu J, Tymianski M, Craig AM, Wang YT. NMDA receptor subunits have differential roles in mediating excitotoxic neuronal death both in vitro and in vivo. J Neurosci 27: 2846-2857 (2007).

[67] Léveillé F, Gaamouch F, Gouix E, Lecocq M, Lobner D, Nicole O, Buisson A. Neuronal viability is controlled by a functional relation between synaptic and extrasynaptic NMDA receptors. FASEB J 22: 4258-4271 (2008).

[68] Tu W, Xu X, Peng L, Zhong X, Zhang W, Soundarapandian MM, Balel C, Wang M, Jia N, Zhang W, Lew F, Chan SL, Chen Y, Lu Y. DAPK1 interaction with NMDA receptor NR2B subunits mediates brain damage in stroke. Cell 140: 222-234 (2010).

[69] Martel M, Wyllie DJ, Hardingham G.E. In developing hippocampal neurons, NR2Bcontaining NMDA receptors can mediate signalling to neuronal survival and synaptic potentiation, as well as neuronal death. Neuroscience 158: 334-343 (2009).

[70] von Engelhardt J, Coserea I, Pawlak V, Fuchs EC, Kohr G, Seeburg PH, Monyer H. Excitotoxicity in vitro by NR2A and NR2B-containing NMDA receptors. Neuropharmacol 53: 10-17 (2007).

[71] Sattler R, Xiong Z, Lu WY, Hafner M, MacDonald JF, Tymianski M. Specific coupling of NMDA receptor activation to nitric oxide neurotoxicity by PS-95 protein. Science 284: 1845-1848 (1999). 
[72] Sheng M. Molecular organization of the postsynaptic specialization. Proc Natl Acad Sci USA 98: 7058-7061 (2001).

[73] Kim E, Sheng M. PDZ domain proteins of synapses. Nat Rev Neurosci 5: 771-781 (2004).

[74] Kornau HC, Schenker LT, Kennedy MB, Seeburg PH. Domain interaction between NMDA receptor subunits and the postsynaptic density protein PSD-95. Science 269: 1737-1740 (1995).

[75] Niethammer M, Kim E, Sheng M. Interaction between the $C$ terminus of NMDA receptor subunits and multiple members of the PSD-95 family of membraneassociated guanylate kinases. J Neurosci 16: 2157-2163 (1996).

[76] Brenman JE, Chao DS, Gee SH, McGee AW, Craven SE, Santillano DR, Wu Z, Huang F, Xia H, Peters MF, Froehner SC, Bredt DS. Interaction of nitric oxide synthase with the postsynaptic density protein PSD-95 and R1-syntrophin mediated by PDZ domains. Cell 84: 757-767 (1996).

[77] Christopherson KS. Hillier J, Lim W A, Bredt D S. PSD-95 assembles a ternary complex with the $N$-methyl-D-aspartic acid receptor and a bivalent neuronal NO synthase PDZ domain. J Biol Chem 274: 27467-27473 (1999).

[78] Iadecola C. Bright and dark sides of nitric oxide in ischemic brain injury. Trends Neurosci 20: 132-139 (1997).

[79] Bolaños JP, Almeida A. Roles of nitric acid in brain hypoxia-ischemia. Biochim Biophys Acta-Bioenerg 1411: 415-436 (1999).

[80] Moro MA, Cárdenas A, Hurtado O, Leza JC, Lizasoain I. Role of nitric oxide after brain ischaemia. Cell Calcium 36: 265-275 (2004).

[81] Arundine M, Tymianski M. Molecular mechanisms of calcium-dependent neurodegeneration in excitotoxicity. Cell Calcium 34: 325-337 (2003).

[82] Aarts M, Liu Y, Liu L, Besshoh S, Arundine M, Gurd JW, Wang YT, Salter MW, Tymiansky $\mathrm{M}$. Treatment of ischemic brain damage by perturbing NMDA receptorPSD-95 protein interactions. Science 298: 846-850 (2002).

[83] Sun H-S, Doucette TA, Liu Y, Fang Y, Teves L, Aarts M, Ryan CL, Bernard PB, Lau A, Forder JP, Salter MW, Wang YT, Tasker A, Tymianski M. Effectiveness of PSD95 inhibitors in permanente and transient focal ischemia in the rat. Stroke 39: 25442553 (2008).

[84] Szydlowska K, Tymiansky M. Calcium, ischemia and excitotoxicity. Cell Calcium 47: 122-129 (2010).

[85] Sattler R, Charlton MP, Hafner M, Tymianski M. Distinct influx pathways, not calcium load, determine neuronal vulnerability to calcium neurotoxicity. J Neurochem 71 : 2349-2364 (1998).

[86] Besancon E, Guo S, Lok J, Tymiansky M, Lo EH. Beyond NMDA and AMPA glutamate receptors: emerging mechanisms for ionic imbalance and cell death in stroke. Trends Pharmacol 29: 268-275 (2008).

[87] Pignarato G, Gala R, Cuomo O, Tortiglione A, Giaccio L, Castaldo P, Sirabella R, Matrone C, Canitano A, Amoroso S, Di Renzo G, Annunziato L. Two sodium/calcium exchanger gene products, NCX1 and NCX3, play a major role in the development of permanent focal cerebral ischemia. Stroke 35: 2566-2570 (2004).

[88] Xiong ZG. Neuroprotection in ischemia: blocking calcium-permeable acid-sensing ion channels. Cell 118: 687-698 (2004).

[89] Bano D, Young KW, Guerin CJ, Lefeuvre R, Rothwell NJ, Naldini L, Rizzuto R, Carasfoli E, Nicotera P. Cleavage of the plasma membrane $\mathrm{Na}^{+} / \mathrm{Ca}^{2+}$ exchager in excitotoxicity. Cell 120: 275-278 (2005). 
[90] Choi DW. Ionic dependence of glutamate neurotoxicity. J Neurosci 7: 369-379 (1987).

[91] Stout AK, Raphael HM, Kanterewicz BI, Klann E, Reynolds IJ. Glutamate-induced neuron death requires mitochondrial calcium uptake. Nat Neurosci 1: 366-373 (1998).

[92] Sattler R, Tymianski M. Molecular mechanisms of calcium-dependent excototoxicity. J Mol Med 78: 3-13 (2000).

[93] Tymianski M, Tator CH. Normal and abnormal calcium homeostasis in neurons: a basis for the pathophysiology of traumatic and ischemic cental nervous system injury. Neurosurgery 38: 1176-1195 (1996).

[94] Choi DW. Calcium- mediated neurotoxicity: relationship to specific channel types and role in ischemic damage. Trends Neurosci 11: 465-467 (1988).

[95] Orrenius S, Zhivotovsky B, Nicotera P. Regulation of cell death: the calcium apoptosis link. Nat Rev Mol Cell Biol 4: 552-565 (2003).

[96] Nicholls DG. Mitochondrial calcium function and dysfunction in the central nervous system. Biochim Biophys Acta 1787: 1416-1424 (2009).

[97] Berridge MJ, Bootman MD, Roderick HL. Calcium signaling: Dinamics, homeostasis and remodelling. Nat Rev Mol Cell Biol 4: 517-529 (2005).

[98] Nicholls DG. Mitochondria and calcium signalling. Cell Calcium 38: 311-317 (2005).

[99] Gunter TE, Pfeiffer DR. Mechanisms by which mitochondria transport calcium. Am J Physiol 258: C755-C786 (1990).

[100] Zaidan E., Sims NR. The calcium content of mitochondria from brain subregions following short-term forebrain ischemia and recirculation in the rat. J Neurochem 63:1282-1289 (1994).

[101] Duchen M. Mitochondria and calcium. From cell signalling to cell death. J Physiol 529: 57-68 (2000).

[102] Piantadosi CA, Zhang J. Mitochondrial generation of reactive oxygen species after brain ischemia in the rat. Stroke 27: 327-331 (1996).

[103] Niizuma K, Endo H, Chan PH. Oxidative stress and mitochondrial dysfunction as determinants of ischemic neuronal death and survival. J Neurosci 109 (Suppl. 1): 133-138 (2009)

[104] Broughton BRS, Reutens D, Sobey CG. Apoptotic mechanisms after cerebral ischemia. Stroke 40: e331-e339 (2009).

[105] Niizuma K, Yoshioka H, Chen H, KimGS, Jung JE, Katsu M, Okami N, Chan PH.: Mitochondrial and apoptotic neuronal death signaling pathways in cerebral ischemia. Biochim Biophys Acta 1802: $92-99$ (2010).

[106] Dröge W. Free radicals in the physiological control of cell function. Physiol Rev 82: 4795 (2002).

[107] Nathan C. Specificity of a third kind: reactive oxygen and nitrogen intermediates in cell signaling. J Clin Invest 111: 769-778 (2003).

[108] D' Autréaux B, Toledano MB. ROS as signalling molecules: mechanisms that generate specificity in ROS homeostasis. Nat Rev Mol Cell Biol 8: 813-824 (2007).

[109] Lin MT, Beal MF. Mitochondrial dysfunction and oxidative stress in neurodegenerative diseases. Nature 443: 787-795 (2006).

[110] Valko M, Leibfritz D, Moncol J, Cronin MTD, Mazur M, Telser J. Free radicals and antioxidants in normal physiological functions and human disease. Int J Biochem Cell Biol 39: 44-84 (2007).

[111] Yu BP. Cellular defenses against damage from reactive oxygen species. Physiol Rev 74:139-162 (1994). 
[112] Fridovich I. Superoxide radical and superoxide dismutases. Annu Rev Biochem 64: 97112 (1995).

[113] Dringen R.: Metabolism and functions of glutathione in brain. Prog Neurobiol 62: 649671 (2000).

[114] Zimmermann C, Winnefeld K, Streck S, Roskos M, Haberl RL. Antioxidant status in acute stroke patients and patients at stroke risk. Eur Neurol 51:157-161 (2004).

[115] Rhee SG, Kang SW, Jeong W, Chang TS, Yang KS, Woo HA. Intracellular messenger function of hydrogen peroxide and its regulation by peroxiredoxins. Curr Opin Cell Biol 17: 183-189 (2005).

[116] Sies H. Oxidative stress: introductory remarks. In: Oxidative Stress. New York: Academic Press, pp. 1-8 (1985).

[117] Halliwell B. Antioxidant defence mechanisms: from the beginning to the end (of the be beginning). Free Radical Res 31: 261-272 (1999).

[118] Orrenius S, Gogvadze V, Zhivotovsky B.: Mitochondrial oxidative stress: implications for cell death. Annu Rev Pharmacol Toxicol 47: 143-183 (2007).

[119] Olanow CW. A radical hypothesis for neurodegeneration. Trends Neurosci 16: 439-444 (1993).

[120] Chan PH: Reactive oxygen radicals in signaling and damage in the ischemic brain. J Cereb Blood Flow Metab 21: 2-14 (2001).

[121] Sugawara T, Chan PH. Reactive oxygen radicals and patogenesis of neuronal death after cerebral ischemia. Antioxid Redox Signal 5: 597-607 (2003).

[122] Nakashima M, Niwa M, Iwai T, Uematsu T. Involvement of free radicals in cerebral vascular reperfusion injury evaluated in a transient focal cerebral ischemia model in rat. Free Radic Biol Med 26: $722-729$ (1999).

[123] Schaller B, Graf R. Cerebral ischemia and reperfusion: the pathophysiologic concept as a basis for clinical therapy. J Cereb Blood Flow Metab 24: 351-371 (2004).

[124] Zhao Q, Pahlmark K, Smith ML, Siesjö BK. Delayed treatment with the spin trap alpha-phenyl-N-tert-butyl nitrone (PBN) reduces infart size following transient middle cerebral artery occlusion in rats. Acta Physiol Scand 152: 349-350 (1994).

[125] Imai H, Graham DI, Masayasu H, Macrae IM. Antioxidant ebselen reduces oxidative damage in focal cerebral ischemia. Free Radic Biol Med 34: 56-63 (2003).

[126] Weisbrot-Lefkowitz M, Reuhl K, Perry B, Chan PH, Inouye M, Mirochnitchenko O. Overexpresion of human glutatión peroxidase protects transgenic mice against focal cerebral ischemia/reperfusion damage. Mol Brain Res 53: 333-338 (1998).

[127] Murakami K, Kondo T, Kawase M, Li Y, Sato S, Chen SF, Chan PH. Mitochondrial susceptibility to oxidative stress exacerbated cerebral infarction that follows permanet focal cerebral ischemia in mutant mice with manganese superoxide dismutase deficiency. J Neurosci 18: 205-213 (1998).

[128] Loschen G, Azzi A, Richter C, Flohe L. Superoxide radicals as precursors of mitochondrial hydrogen-peroxide. FEBS Lett 42: 68-72 (1974).

[129] Turrens JF. Superoxide production by the mitocondrial respiratory chain. Biosci Rep 17: 3-8 (1997).

[130] Andreyev AY, Kushnareva YE, Starkov AA. Mitochondrial metabolism of reactive oxygen species. Biochemistry 70: 200-214 (2005).

[131] Cooper AJL, Kristal BS.: Multiple roles of glutathione in the central nervous system. Biol Chem 378:793-802 (1997).

[132] Kinuta Y, Kikuchi H, Ishikawa M, Kimura M, Itokawa Y. Lipid peroxidation in focal cerebral ischemia. J Neurosurg 71: 421-429 (1989). 
[133] Kuroda S, Katsura K, Hillered L, Bates TE, Siesjo BK. Delayed treatment with alphaphenyl-N-tert-butyl nitrote (PBN) attenuates secondary mitochondrial dysfunction after transient focal cerebral ischemia in the rat. Neurobiol Dis 3:149-57 (1996).

[134] Xu L, Voloboueva LA, Ouyang Y, Emery JF, Giffard RG. Overexpression of mitochondrial Hsp70/Hsp75 in rat brain protects mitochondria, reduces oxidative stress, and protects from focal ischemia. J Cereb Blood Flow Metab 29: 365-374 (2009).

[135] Suh SW, Shin BS, Ma H, Van Hoecke M, Brennan AM, Yenari MA, Swanson RA. Glucose and NADPH oxidase drive neuronal superoxide formation in stroke. Ann Neurol 64: 654-663 (2008).

[136] Bedard K, Krause KH. The NOX family of ROS-generating NADPH oxidases: physiology and pathophysiology. Physiol Rev 87: 245-313 (2007).

[137] Chen H, Song YS, Chan P. Inhibition of NADPH oxidase is neuroprotective after ischaemia-reperfusion. J Cereb Blood Flow Metab 29: 1262-1272 (2009).

[138] Umemura A, Mabe H, Nagai H, Supino F. Action of phospholipases A2 and C on free $\mathrm{ftty}$ acid release during complete ischemia in rat neocrtex. Effect of phospholipase C inhibitor and N-methyl-D-aspartate antagonist. J Neurosurg 76: 648-651 (1992).

[139] Muralikrishna Adidhatla R, Hatcher JF. Phospholipase A2, reactive oxygen specis, and lipid peroxidation in cerebral ischemia. Free Rad Biol Med 40: 376-387 (2006).

[140] Dumuis M, Sebben H, Haynes JP, Pin J, Bockaert A. NMDA receptors activate the arachidonic acid cascade system in striatal neurons. Nature 336: 68-70 (1988).

[141] Beckman JS. Peroxynitrite versus hydroxyl radical: the role of nitric oxide in superoxide-dependent cerebral injury. Ann N Y Acad Sci 738: 69-75 (1994).

[142] Castillo J, Rama R, Dávalos A. Nitric oxide-related brain damage in acute ischemic stroke. Stroke 31: 852-857 (2000).

[143] Liochev SI, Fridovich I. The Haber-Weiss cycle-70 years later: An alternative view. Redox Rep 7: 55-57 (2002).

[144] Winterbourn CC. Toxicity of iron and hydrogen peroxide: The Fenton reaction. Toxicol Lett 969: 82-83 (1995).

[145] Grune T, Reinheckel T, Davies KJA. Degradation of oxidized proteins in mammalian cells. FASEB J 11: 526-534 (1997).

[146] Krupinski J, Lopez E, Marti E, Ferrer I. Expression of caspases and their substrates in the rat model of focal cerebral ischemia. Neurobiol Dis 7 332-342 (2000).

[147] Culmsee C, Mattson MP. p53 in neuronal apoptosis. Biochem Biophys Res Commun 331: 761-777 (2005).

[148] Green DR, Kroemer G. The pathophysiology of mitochondrial cell death. Science 305: 626-629 (2004).

[149] Elmore S.: Apoptosis: a review of programmed cell death. Toxicol Pathol 35: 495-516 (2007).

[150] Frankowski H, Missotten M, Albertini P, Talabot D, Catsicas S, Pietra C, Huarte J. Overexpression of BCL-2 in transgenic mice protects neurons from naturally occurring cell death and experimental ischemia. Neuron 13: 1017-1030 (1994).

[151] Crumrine RC, Thomas AL, Morgan PF. Attenuation of p53 expression protects against focal ischemic damage in transgenic mice. J Cereb Blood Flow Metab 14:887-891 (1994).

[152] Liu J, Liu MC, Wang KK. Calpain in the CNS: from synaptic function to neurotoxicity. Sci Signal 1: re 1 (2008). 
[153] Goll DE, Thompson VF, Li HQ, Wei W, Cong JY. The calpain system. Physiol Rev 83: 731-801 (2003).

[154] Rami A, Ferger D, Krieglstein J. Blockage of calpain proteolytic activity rescues neurons from glutamate excitotoxicity. Neurosci Res 27: 93-97 (1997).

[155] Ray SK. Currently evaluated calpain and caspase inhibitors for neuroprotection in experimental brain ischemia. Curr Med Chem13: 3425-3440 (2006).

[156] Bevers MB, Neumar RW. Mechanistic role of calpains in postischemic neurodegeneration. J Cereb Blood Flow Metab 28: 655-673 (2008).

[157] Bano D, Nicotera P. Ca ${ }^{2+}$ signals and neuronal death in brain. Stroke 38 [part 2]: 674676 (2007).

[158] Heiss WD, Thiel A, Grond M, Graf R. Which targets are relevant for therapy of acute ischemic stroke? Stroke 30:1486-1489 (1999).

[159] Tissue plasminogen activator for acute ischemic stroke. The National Institute of Neurological Disorders and Stroke rt-PA Stroke Study Group. N Engl J Med 333: 1581-87 (1995).

[160] Reeves MJ, Arora S, Broderick JP, et al. Acute stroke care in the US: results from the 4 pilot prototypes of the Paul Coverdell National Acute Stroke Registry. Stroke 36: 1232-1240 (2005).

[161] Caplan LR. Stroke thrombolysis: slow progress. Circulation 114: 187-190 (2006).

[162] Derex L, Nighoghossian N. Intracerebral haemorrhage after thrombolysis for acute ischaemic stroke: an update. J Neurol Neurosurg Psychiatry 79: 1093-1099 (2008).

[163] Molina CA, Saver JL. Extending reperfusion therapy for acute ischemic stroke: emerging pharmacological, mechanical, and imaging strategies. Stroke 36: 2311-2320 (2005).

[164] O’Collins VE, McLeod MR, Donnan GA, HorkyLL, van der Worp BH, Howells DW. 1026 experimental treatments in acute stroke. Ann Neurol 50: 447-448 (2006).

[165] Ginsberg MD. Neurprotection for ischemic stroke: past, present and future. Neuropharmacol 55: 363-389 (2008).

[166] Fisher M. New approaches to neuroprotective grug development. Stroke 42 [suppl 1]: S24-S27 (2011).

[167] Fisher M, Feuerstein GZ, Howells DW, Hurn PD, Kent TA, Savitz SI, Lo EH (for the STAIR group). Update for the Stroke Therapie Academic Industry Roundtable preclinical recommendations. Stroke 40: 2244-2250 (2009).

[168] Stankowski JN, Gupta R. Therapeutic targets for neuroprotecion in acute ischemic stroke: lost in translation?. Antioxid Redox Signal 14: 1841-1851 (2011).

[169] Bernaudin M, Marti HH, Roussel S, Divoux D, Nouvelot A, MacKenzie ET, Petit E. A potential role for erythropoietin in focal permanent cerebral ischemia in mice. J Cereb Blood Flow Metab 19: 643-651 (1999).

[170] Siren AL, Fratelli M, Brines M, Goemans C, Casagrande S, Lewczuk P, Keenan S, Gleiter C, Pasquali C, Capobianco A Mennini T, Heumann R, Cerami A, Ehrenreich $\mathrm{H}$, Ghezzi P. Erythropoietin prevents neuronal apoptosis after cerebral ischemia and metabolic stress. Proc. Natl Acad Sci USA 98: 4044-4049 (2001).

[171] Kilic E, Kilic U, Soliz J, Bassetti CL, Gassmann M, Hermann DM. Brain-derived erythropoietin protects from focal cerebral ischemia by dual activation of ERK-1/-2 and Akt pathways. FASEB J 19: 2026-2028 (2005).

[172] Reitmer R, Kilic E, Kilic Ü, Bacigaluppi M, ElAli A, Salani G, Pluchino S, Gassmann M, Hermann DM. Post-acute delivery of erythropoietin induces stroke recovery by promoting perilesional tissue remodelling and contralesional pyramidal tract plasticity. Brain 134: 84-99 (2011). 


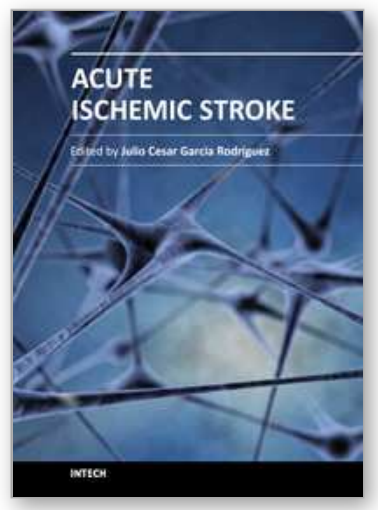

\author{
Acute Ischemic Stroke \\ Edited by Prof. Julio Cesar Garcia Rodriguez
}

ISBN 978-953-307-983-7

Hard cover, 236 pages

Publisher InTech

Published online 18, January, 2012

Published in print edition January, 2012

Despite significant technological advances in recent years, their impact on our overall health and social, wellbeing is not always clear to see. Perhaps, one of the best examples of this can be highlighted by the fact that mortality rates as a result of cerebrovascular diseases have hardly changed, if at all. This places cerebrovascular diseases as one of the most prominent causes of both disability and death. In Cuba, for instance, a total of 22,000 cases of cerebrovascular diseases are reported each year in a country where life expectancy should increase to 80 years in the near future. In such a situation, to have a book that includes in a clear and summarized way, a group of topics directly related to the preclinical investigations advances and the therapeutic procedures for the cerebrovascular disease in its acute phase constitutes a useful tool for the wide range of the contributors to this affection's problems solution. In this group is included students, professors, researchers, and health policy makers whose work represents one of the greatest social and human impact challenges of the XXI century basic and clinical neurosciences.

\title{
How to reference
}

In order to correctly reference this scholarly work, feel free to copy and paste the following:

Ramón Rama Bretón and Julio César García Rodríguez (2012). Excitotoxicity and Oxidative Stress in Acute Ischemic Stroke, Acute Ischemic Stroke, Prof. Julio Cesar Garcia Rodriguez (Ed.), ISBN: 978-953-307-983-7, InTech, Available from: http://www.intechopen.com/books/acute-ischemic-stroke/excitotoxicity-and-oxidativestress-in-acute-ischemic-stroke

\section{INTECH}

open science | open minds

\section{InTech Europe}

University Campus STeP Ri

Slavka Krautzeka 83/A

51000 Rijeka, Croatia

Phone: +385 (51) 770447

Fax: +385 (51) 686166

www.intechopen.com

\section{InTech China}

Unit 405, Office Block, Hotel Equatorial Shanghai

No.65, Yan An Road (West), Shanghai, 200040, China

中国上海市延安西路65号上海国际贵都大饭店办公楼405单元

Phone: +86-21-62489820

Fax: $+86-21-62489821$ 
(C) 2012 The Author(s). Licensee IntechOpen. This is an open access article distributed under the terms of the Creative Commons Attribution 3.0 License, which permits unrestricted use, distribution, and reproduction in any medium, provided the original work is properly cited. 